\title{
A systematic literature review on activity recognition with context-awareness techniques for mitigation of disasters
}

\section{Fatai Idowu Sadiq}

Faculty of Computing,

Universiti Teknologi Malaysia,

81310, Skudai, Johor Bahru, Malaysia

and

Department of Computer Science,

Ambrose Ali University,

P.M.B. 14, Ekpoma, Edo-State, Nigeria

Email: fisadiqcsc-dpt@aauekpoma.edu.ng

\author{
Ali Selamat* \\ UTM-IRDA Digital Media Center of Excellence, \\ Universiti Teknologi Malaysia, \\ 81310, Skudai, Johor Bahru, Malaysia \\ Email: aselamat@utm.my \\ and \\ Faculty of Computing, \\ Universiti Teknologi Malaysia, \\ 81310, Skudai, Johor Bahru, Malaysia \\ and \\ Centre for Basic and Applied Research, \\ Faculty of Informatics and Management, \\ University of Hradec Kralove, \\ Rokitanskeho 62, Hradec Kralove, 50003, Czech Republic \\ *Corresponding author
}

\section{Roliana Ibrahim}

Faculty of Computing,

Universiti Teknologi Malaysia,

81310, Skudai, Johor Bahru, Malaysia

Email: roliana@utm.my

\begin{abstract}
This paper presents a systematic literature review on context-awareness using activity recognition for mitigation of disasters. Disaster preparedness and the method of mitigating it or reduction of causalities are very important in order to save human lives. The review process went through four phases which are: planning, collation, filtration of dataset to get the most relevant materials, exploration and the description based on findings was carried out. The problem with the existing studies are: technology used lack the capacity to give feedback to potential victims, inability to move
\end{abstract}


the technology around, high false negative alarm, low sensor quality for crowd behaviour monitoring. This study used smartphones which is handy and has potential of being carried about. The analysis of the result was presented under three major headings which are publication by year, techniques, results and findings. The result shows the research gap in the area of disaster mitigation and the further study suggests the need to extend context-aware framework for stampede prediction based on activity recognition accuracy used in the previous study.

Keywords: systematic literature review; SLR; activity recognition accuracy; ARAC; smartphone sensor; crowd disasters; context-awareness.

Reference to this paper should be made as follows: Sadiq, F.I., Selamat, A. and Ibrahim, R. (2018) 'A systematic literature review on activity recognition with context-awareness techniques for mitigation of disasters', Int. J. Digital Enterprise Technology, Vol. 1, Nos. 1/2, pp.177-217.

Biographical notes: Fatai Idowu Sadiq is a Lecturer from the Ambrose Alli University, Ekpoma, Nigeria. He obtained his BTech/Maths and MTech in Computer Science in Minna and Akure. He obtained his MBA and PGD in Education from the Ambrose Alli University, Ekpoma and MPhil in Computer Science in Nigeria. He is currently a PhD Scholar at the Faculty of Computer Science and Information Systems in the Universiti Teknologi Malaysia. He is a member of Nigeria Computer Society (NCS), Computer Professional, Registration Council of Nigeria (CPN) and IEEE Computer Society. His research interest are context-aware computing, human activity recognition and disaster management. He has published number of papers in both local and international journals

Ali Selamat is currently a Chief Information Officer and Director of Centre for Information and Communication Technologies at the Universiti Teknologi Malaysia (UTM), Malaysia. He is also a Professor in the Software Engineering Department at the Faculty of Computing, UTM. He is nominated as the Vice Chair of the IEEE Computer Society Malaysia since 2014. Currently, he is the editor of International Journal of Intelligent Information Database Systems (IJIIDS), Inderscience Publisher. His research interests include software engineering, software process improvement, software agents, web engineering, information retrievals, pattern recognition, genetic algorithms, neural networks and soft computing, computational collective intelligence, strategic management, key performance indicator and knowledge management.

Roliana Ibrahim is the Head of the Information Systems Department, Faculty of Computing, Universiti Teknologi Malaysia (UTM). She received her BSc (Honours) in Computer Studies from the Liverpool John Moores University, MSc in Computer Science from the Universiti Teknologi Malaysia and $\mathrm{PhD}$ in the field of Systems Engineering from the Loughborough University. She has been an academic staff at Information Systems Department since 1999 and was previously a Coordinator of BSc in Computer Science (Bioinformatics) Program and Master of Information Technology (IT Management). She is one of the editorial board members of Journal of Information Systems Research and Innovation (JISRI) and the Guest Chief Editor of Special Issue on Science and Technology, Jurnal Teknologi UTM.

This paper is a revised and expanded version of a paper entitled 'Context-awareness with activity recognition for mitigation of crowd disasters: a systematic literature review', presented at International Graduate Conference on Engineering, Science and Humanities (IGCESH 2016), Universiti Teknology Malaysia, Skudai, 81310, N24 Building, August 2016. 


\section{Introduction}

Context-aware computing (CAC) is a software that examines and reacts to individual's changing context (Schilit et al., 1994). It is aware of the user's state and surroundings and helps to adapt to its behaviour (Satyanarayanan, 2002). The term context-awareness is a property of mobile computing. It originates as a term from ubiquitous or pervasive computing, which is an act of linking changes in the environment with a computer system that is static. The current target of pervasive computing is how to integrate intelligent agent that is capable of knowledge empowerment and reasoning to understand the local context and shared information to support intelligent application and interfaces (Chen et al., 2003). Contextual characteristics experience changes when the need arises, by using contextual commands, automatic contextual reconfiguration and context triggered actions (Schilit et al., 1994). Any CA software will use any of these contextual commands, automatic contextual reconfiguration or context trigger actions to execute the expected task to carry out its function. Present researches with context-awareness application are common in campuses (Hsieh et al., 2007), industries (Docter et al., 2007), healthcare services (Varshney, 2009), other organisations and the entire world. Previous research has shown that CA personalised activity assistance will act as a commonplace in the future. The smart home activities of daily living of people, particularly elderly or disabled can be monitored and analysed for personalised CA assistance living to be offered. Hence, activity recognition (AR) has emerged as a critical research issue related to the realisation of intelligence in pervasive environments. Context is any information that can be used to characterise the situation of an entity. The entities include identity (who); activity (what); time (when); and location (where) in other words, W4 can be used to describe context in Abowd et al. (1998). However, contextual information and any intelligent behaviour in an environment need to be relevant to the user's context and ongoing activities. This concept led to AR that has emerged as a final research issue related to the successful realisation of intelligent pervasive environments. A systematic literature review (SLR) is a product of evidence-based software engineering (EBSE) concept proposed in Kitchenham and Charters (2007). It is simply a "standard for identifying, evaluating and interpreting all available research that is relevant to a specific question, topic area or phenomenon of interest." However, some studies present a literature review on CA related research in Hong et al. (2009), Orwat et al. (2008), Naismith et al. (2004), Ye et al. (2012) and Al-Bashayreh et al. (2013), from our beast knowledge, only Al-Bashayray et al. (2013), have conducted a systematic review of CA mobile patient monitoring framework (CMPMF). Al-Bashayray et al. (2013) adapted the 'concept matrix technique' to synthesise previous studies to develop a research agenda, which further provides foundation for extending the state-of-the-art research by filling the gaps identified. The study also categorised previous work using factors of strong context-aware application framework (FSCAF), to enhance the design of CMPMF and to address the problems encountered in mobile patient monitoring systems (MPMS) using wireless sensors, in the field of biomedical informatics with patients having chronic diseases; like hypertension, diabetes and epilepsy; in respect of vital sign, medication treatment and disease symptoms. A good scientific and quality literature review is a prerequisite for doing excellent and creative research. Quality research is quality because it promotes and expands our horizon and the overall perception on the research. Given this fact, this paper explores context-awareness techniques using AR related research 
with focus on mitigation of disasters in particular, crowd disaster. In the light of this, this study carries out SLR in context-awareness with a focus on AR domain that addresses problems in a crowd disaster mitigation (DM) related topics.

Q1 What are the existing context-awareness techniques with AR?

Q2 What are the strength and weaknesses?

Q3 What are the contributions in context-awareness with AR related to DM?

Q4 Which of this CA AR researches address crowd disaster?

Meanwhile, the main contributions of this paper are outline as follows:

1 To present a SLR to identify the context-awareness techniques associated with AR.

2 To highlight the strengths and weaknesses of the identified techniques using the SLR.

3 To investigate and identify the context-awareness techniques with AR appropriate to solve disaster related problems thereby extending the study of Ramesh et al. (2014) and similar study found in literature.

4 To highlights the techniques that can help to mitigate crowd disaster to minimise loss of lives and properties in the 21 st century and beyond.

The remaining sections are as follows, Section 2 explains flow of the research methodology adopted and research questions (RQs) used in this study. In Section 3, results and statistics of primary studies are presented. Section 4 discussed the various results to provide answers to the RQs (Q1-Q4), Section 5 discusses research activity issue in a crowd DM, existing context-awareness frameworks, important research gaps with future research directions and Section 6 presents the conclusions.

\subsection{Problem background}

Previous studies focus on the use of close circuit television (CCTV), as far back as 1995 (Schilit et al., 1994), video camera in computer vision (Satyanarayanan, 2002), for monitoring people in the crowd to provide safety measure, in the case of unforeseen incidents. These techniques suffer from:

1 no feedback to the potential victims of danger

2 the device which is normal position in a specific location due to their static nature

3 devices are hardly found among people except in rear cases like smartphone.

Wireless sensor network was remarked to be suitable for better situational awareness of crowd monitoring in a crowded area (Chen et al., 2003). Despite this, it has limitations such as:

1 high false negative alarm (FNA)

2 low sensor quality for crowd behaviour recognition.

Presently, the research has shifted to the use of context-awareness computing and wireless sensor network (Hsieh et al., 2007). Because of the evolution of smartphone 
sensing and the power of inbuilt sensors with the tendency to monitor and sensitise potential victims of danger for any unforeseen incidents that can cause a disaster during an emergency with feedback to reduce risk associated with such occurrences. Figure 1 depicts the overview of scenarios based on the issues that led to existing studies (Docter et al., 2007; Varshney, 2009) that led to the existing studies.

Figure 1 Flow of crowd monitoring system issues (see online version for colours)

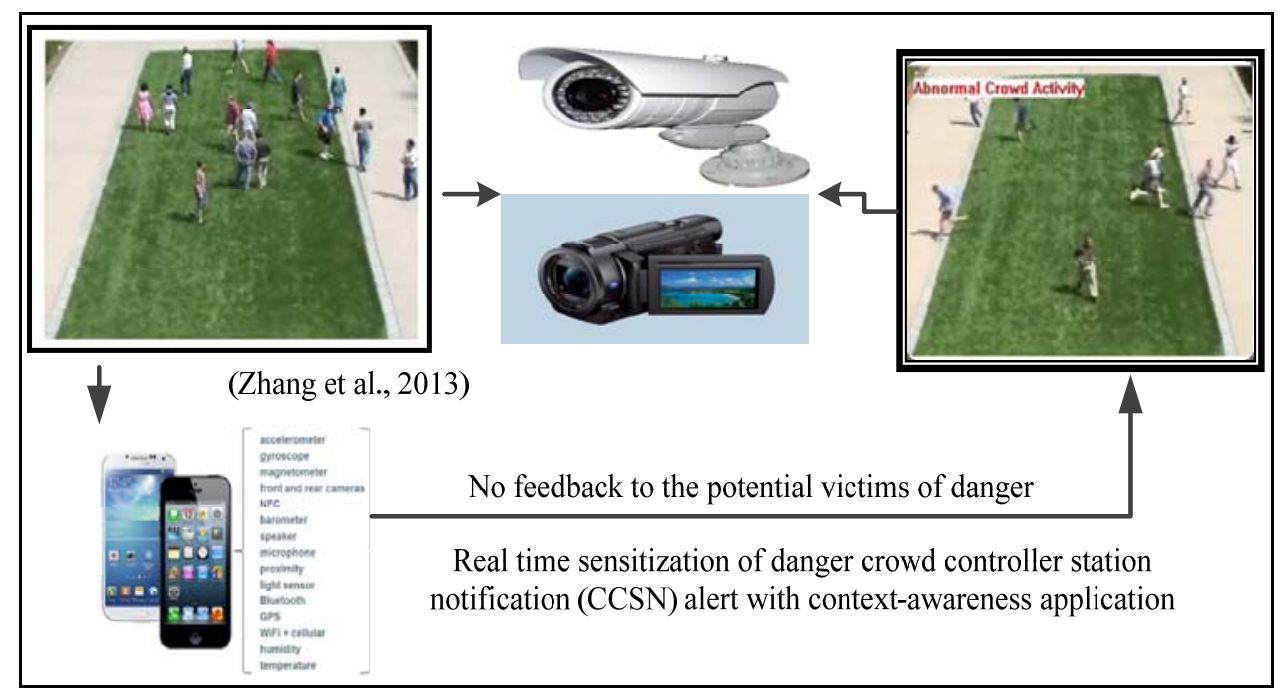

\section{Methodology}

The various stages of a SLR are employed in this paper. Following the first stage presented in conference refer to Sadiq et al. (2016). The steps comprise of planning, conducting and documenting the review (Kitchenham and Charters, 2007; Achimugu et al., 2014). Each step involves combinations of simple procedures that will guide to achieve the goal of this study. The paper focus on the investigation of several issues concerning research on context-awareness and the extent to which it has been used to handle disaster management. It also focuses on SLR using combined approach and guidelines adapted from Naismith et al. (2004), Glass et al. (2002) and Musumba and Nyongesa (2013). The authors of the said study utilised four phases method to plan, collate, explore and described the literature-based discoveries. In this study, the focus is to employ a SLR approach to selected related publications and explanation on the under listed RQs.

Q1 What are the existing context-awareness techniques with AR?

Q2 What are the strength and weaknesses?

Q3 What are the contributions in context-awareness with AR related to DM?

Q4 Which of this CA AR researches address crowd disaster? 


\subsection{SLR approach}

The study proceeds on SLR using the design flow showing six main steps in a way that each of them is important to the proposed study.

Figure 2 Design flow of the SLR approach

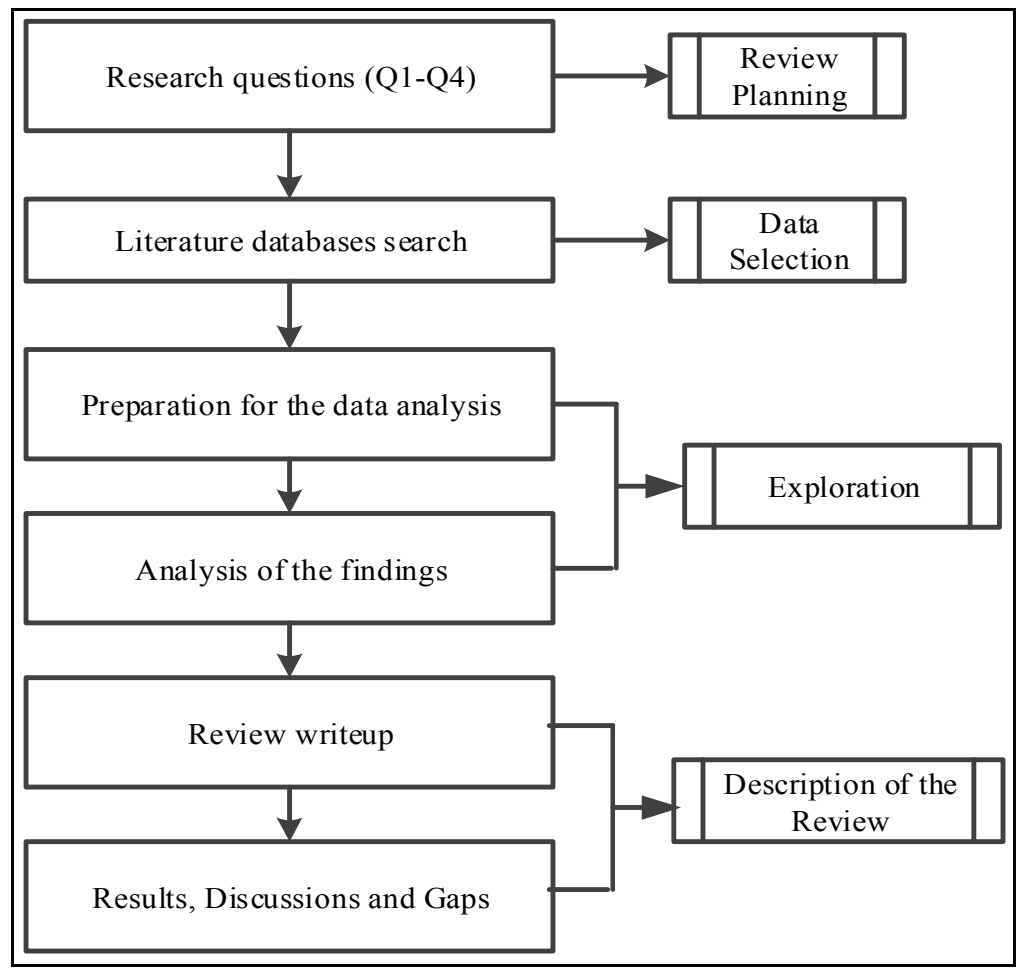

\subsubsection{Search process}

SLR deals with a comprehensive search of all relevant sources about the subject of discussion. However, the search process used in this study is classified into two main search stages. Search:

Step 1 A thorough search was launched on the four electronic database sources and the returned results (papers) were assembled as a set of prospective papers from high-quality journals and the web of science.

Step 2 The reference lists of all quality papers were read to pick additional quality papers, if any, combine them with the relevant ones.

The design flow following the first stage of this research presented in is as shown in Figure 2.

The summary of the search process and criteria for selecting the selected primary studies depicts Figure 3. 
Figure 3 Flow of the SLR study databases and adopted search criteria

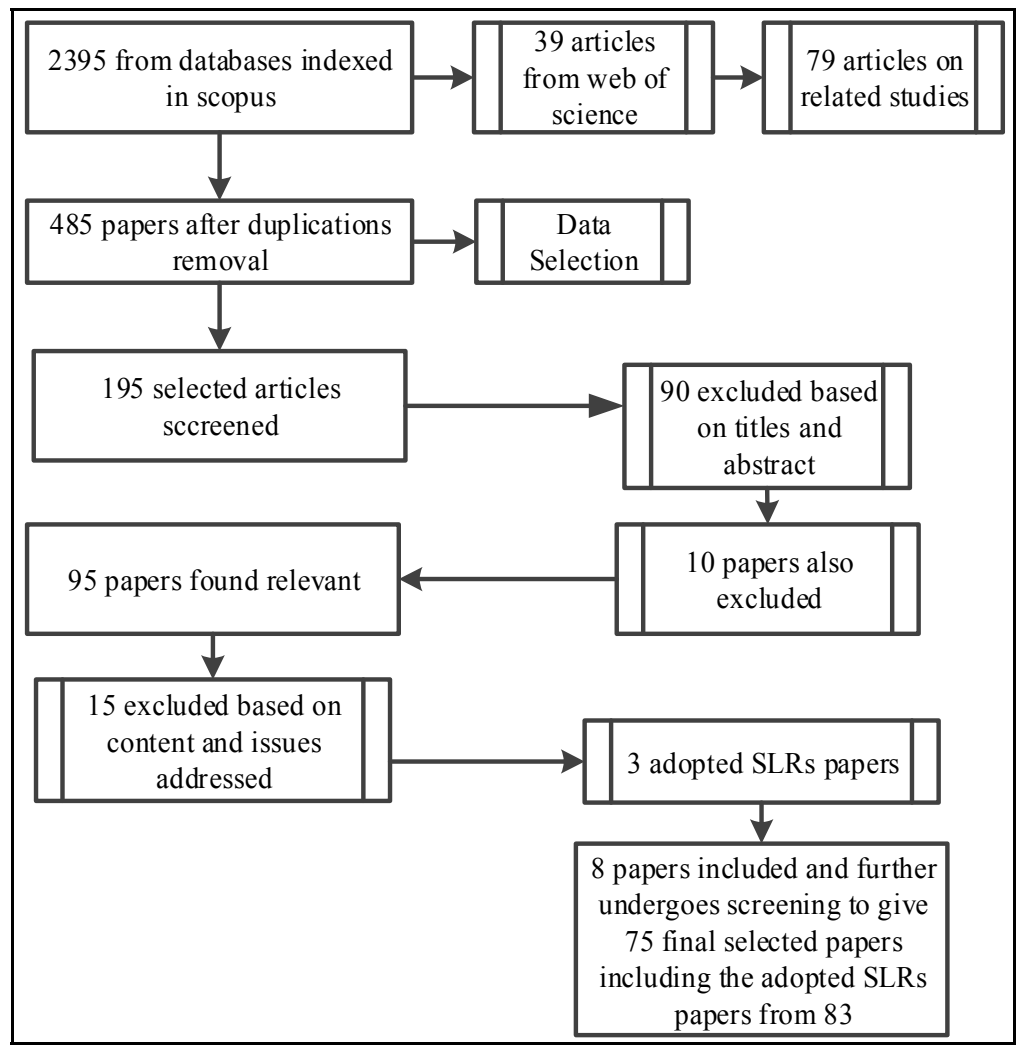

\subsection{Search terms}

The under listed search terms were used for obtaining relevant studies as a result of the topic of discussion. The terms are as follows: "context-awareness, CA technique and shortcoming of CA techniques, AR and CA and mitigation of crowd disasters." The search terms were further modified as follows:

1 Identifying the key terms in the RQs formulated in Section 2.

2 Identifying different spellings and substitutes of key terms.

3 Accessing the index terms of relevant publications.

4 Embedding the Boolean OR in alternative spellings and synonyms.

5 Embedding the Boolean AND between links of key terms.

\subsubsection{Study selection}

From the first search stage, 2,395 prospective studies were realised. Next, the titles of these studies were used to scrutinise and collate relevant studies. This task was necessary 
to eliminate duplicate and irrelevant studies. Consequently, 95 relevant studies were selected. After that, the keywords and references on each selected study were perused to determine important studies that might have been missed out during the initial search process. This effort led to the identification of 15 additional studies that were further screened out of the initial search process that took the tally of the selected studies to 75 from 83 plus SLR papers. The 75 primary studies (Table 3 ) may be as a result of the domain of focus in this study though other disasters-related works were found in the literature, they do not address the topic under consideration. Finally, the quality criteria stipulated in Table 1 used for scrutiny were applied to the 75 relevant studies discovered, thus form the final selected studies that are capable of providing answers to the formulated set of RQs.

Table 1 Inclusion and exclusion criteria

\begin{tabular}{lll}
\hline Inclusion criteria & & \multicolumn{1}{c}{ Exclusion criteria } \\
\hline a $\quad \begin{array}{l}\text { Published papers written in English } \\
\text { language }\end{array}$ & a & $\begin{array}{l}\text { Published papers not written in English } \\
\text { language }\end{array}$ \\
b $\begin{array}{l}\text { Papers that focus on context-aware and } \\
\text { activity recognition or address disaster } \\
\text { issues }\end{array}$ & b & $\begin{array}{l}\text { Papers that do not answer any of the } \\
\text { research questions }\end{array}$ \\
c $\quad \begin{array}{l}\text { Relevant papers that are published } \\
\text { previously until 2017 }\end{array}$ & c & Papers without proper reference information \\
d $\begin{array}{l}\text { Papers with publishing details } \\
\text { e } \quad \begin{array}{l}\text { All published papers whose contents are } \\
\text { related to the research questions } \\
\text { formulated }\end{array}\end{array}$ & d & $\begin{array}{l}\text { Paper not yet published but in press with } \\
\text { reference criteria } \\
\text { Duplicate papers were excluded (papers that } \\
\text { are similar in content or address same topics } \\
\text { or have the same contributions) }\end{array}$ \\
\hline
\end{tabular}

\subsubsection{Scrutiny}

From Figure 3, 2,395 prospective studies were obtained during the first search process. Therefore, scrutiny was necessary to streamline the studies to relevant ones. First, the title of each study was considered then, their contents were briefly studied. Meanwhile, all the papers that do not reflect the topic of discussion or are incapable of addressing any of the formulated RQs were expunged from the relevant studies list. Also, only studies written and published in English language from peer-reviewed journals referred conference proceedings, workshops, book chapters, IEEE published and relevant journals were considered for inclusion in the list of relevant studies. However, when multiple copies of the same paper appeared, the most complete, recent and improved journal is included in the search processes while the irrelevant articles which does not address problem considered in this study are excluded.

\subsubsection{Quality assessment}

The quality assessment score shown in Table $2^{1}$ utilises a score criteria described in this section. Publication topics, CA research that addresses general context interactions issues such as acquisition, modelling and inference or research on AR or those that focus on $\mathrm{DM}$ issues, such publication is assigned score $=1$. Literature which discussed both CA and AR; CA and focuses on DM; or AR and focuses on DM, such publication(s) is 
assigned score $=2$. The paper that dealt with CA and AR and focuses on DM related issues such paper is assigned score $=3$. The entire scores are then summarised in each column and used to determine the quality of the paper(s). Since all were summed up to $100 \%$; the average quality score obtained from Table 2 is $33.3 \%$. Any score below $33.3 \%$ is of low quality, hence, research in such area is low, thus opens the opportunity for further research. In addition, publications which address either one of CA or AR or DM only are $59 * 1:(55.14 \%)$; those with both CA and AR, CA and DM or AR and DM are $12 * 2=24:(22.43 \%)$ and those that addressed CA with AR and DM are $8 * 3=24$ : $(22.43 \%)$.

\subsection{Data collection}

After the paper inclusion and exclusion criteria process, the collated papers which represents dataset of the primary studies are presented in Table 3. In the data collection stage, the authors' extracted different attributes from the primary studies. The extracted attributes from various papers detail are as follows:

- $\quad$ publisher (IEEE, Springer, ScienceDirect, ACM, other journal)

- type of publication (conference, book chapter, workshop, journal)

- $\quad$ published (journal or conference name)

- publication name

- country

- year of publication

- classification based on research activity

- classification based on techniques

- classification based on research contribution

- classification based on problem domain.

\subsubsection{Classification approach}

Scientific research papers are normally categorised based on their methods and approach. Glass et al. (2002), Musumba and Nyongesa (2013) and Ramesh et al. (2014) ${ }^{2}$ have identified context acquisition, sensing, modelling, inference (Lee et al., 2014; Schmidt, 2013; Champiri et al., 2015) as contending issues in context-awareness services using context interaction. The classification used in this study is employed from similar SLR research articles such as Ampatzoglou and Stamelos (2010), relating the whole idea to the concept of research of interest conducted in this study. The key scientific approach categories explained in Glass et al. (2002) includes empirical, exploratory and descriptive approaches. Empirical reveal findings of direct or indirect observation of physical or actual subjects; exploratory approach assists in the determination of the best research design, the data collection method and selection of subject; it is used under a situation where the research problem is not clearly defined. On the other hand, a descriptive paper normally describes a system such as tool or methods. 
Table 2 Quality assessment

\begin{tabular}{|c|c|c|c|c|c|c|c|}
\hline References & 1 & 2 & 3 & References & 1 & 2 & 3 \\
\hline $\mathrm{C} 1$ & $\checkmark$ & & & $\mathrm{C} 35$ & $\checkmark$ & & \\
\hline $\mathrm{C} 2$ & $\checkmark$ & & & $\mathrm{C} 36$ & & $\checkmark$ & \\
\hline $\mathrm{C} 3$ & $\checkmark$ & & & C37 & & $\checkmark$ & \\
\hline $\mathrm{C} 4$ & $\checkmark$ & & & C38 & & $\checkmark$ & \\
\hline $\mathrm{C} 5$ & $\checkmark$ & & & C39 & & $\checkmark$ & \\
\hline C6 & & $\checkmark$ & & $\mathrm{C} 40$ & & $\checkmark$ & \\
\hline C7 & $\checkmark$ & & & $\mathrm{C} 41$ & $\checkmark$ & & \\
\hline $\mathrm{C} 8$ & $\checkmark$ & & & C42 & $\checkmark$ & & \\
\hline C9 & $\checkmark$ & & & $\mathrm{C} 43$ & $\checkmark$ & & \\
\hline $\mathrm{C} 10$ & $\checkmark$ & & & C44 & & $\checkmark$ & \\
\hline $\mathrm{C} 11$ & $\checkmark$ & & & $\mathrm{C} 45$ & $\checkmark$ & & \\
\hline $\mathrm{C} 12$ & $\checkmark$ & & & $\mathrm{C} 46$ & & $\checkmark$ & \\
\hline $\mathrm{C} 13$ & & $\checkmark$ & & C47 & & $\checkmark$ & \\
\hline $\mathrm{C} 14$ & $\checkmark$ & & & $\mathrm{C} 48$ & & $\checkmark$ & \\
\hline $\mathrm{C} 15$ & $\checkmark$ & & & C49 & $\checkmark$ & & \\
\hline C16 & $\checkmark$ & & & C50 & $\checkmark$ & & \\
\hline $\mathrm{C} 17$ & $\checkmark$ & & & $\mathrm{C} 51$ & $\checkmark$ & & \\
\hline $\mathrm{C} 18$ & $\checkmark$ & & & C52 & $\checkmark$ & & \\
\hline C19* & & & $\checkmark$ & C53 & $\checkmark$ & & $\checkmark$ \\
\hline $\mathrm{C} 20$ & $\checkmark$ & & & C54 & $\checkmark$ & & \\
\hline $\mathrm{C} 21$ & $\checkmark$ & & & $\mathrm{C} 55$ & $\checkmark$ & & \\
\hline $\mathrm{C} 22$ & $\checkmark$ & & & C56 & $\checkmark$ & & \\
\hline $\mathrm{C} 23$ & & & $\checkmark$ & C57 & $\checkmark$ & & $\checkmark$ \\
\hline $\mathrm{C} 24$ & $\checkmark$ & & & C58 & $\checkmark$ & & \\
\hline $\mathrm{C} 25$ & $\checkmark$ & & & C59 & $\checkmark$ & & \\
\hline $\mathrm{C} 26$ & $\checkmark$ & & & C60 & $\checkmark$ & & \\
\hline $\mathrm{C} 27$ & $\checkmark$ & & & C61 & $\checkmark$ & & \\
\hline $\mathrm{C} 28$ & $\checkmark$ & & & C62 & $\checkmark$ & & \\
\hline $\mathrm{C} 29$ & & & $\checkmark$ & C63 & $\checkmark$ & & $\checkmark$ \\
\hline $\mathrm{C} 30$ & & & $\checkmark$ & C64 & $\checkmark$ & & $\checkmark$ \\
\hline $\mathrm{C} 31$ & $\checkmark$ & & & C65 & $\checkmark$ & & \\
\hline C32 & & $\checkmark$ & & C66 & $\checkmark$ & & \\
\hline $\mathrm{C} 33$ & $\checkmark$ & & & C67 & $\checkmark$ & & \\
\hline C34 & $\checkmark$ & & & $\mathrm{C} 68-\mathrm{C} 75$ & $\checkmark$ & & \\
\hline
\end{tabular}

Note: * is the baseline line study that led to the motivation of this SLR in disaster mitigation presented in this paper. 
Table 3 Study dataset

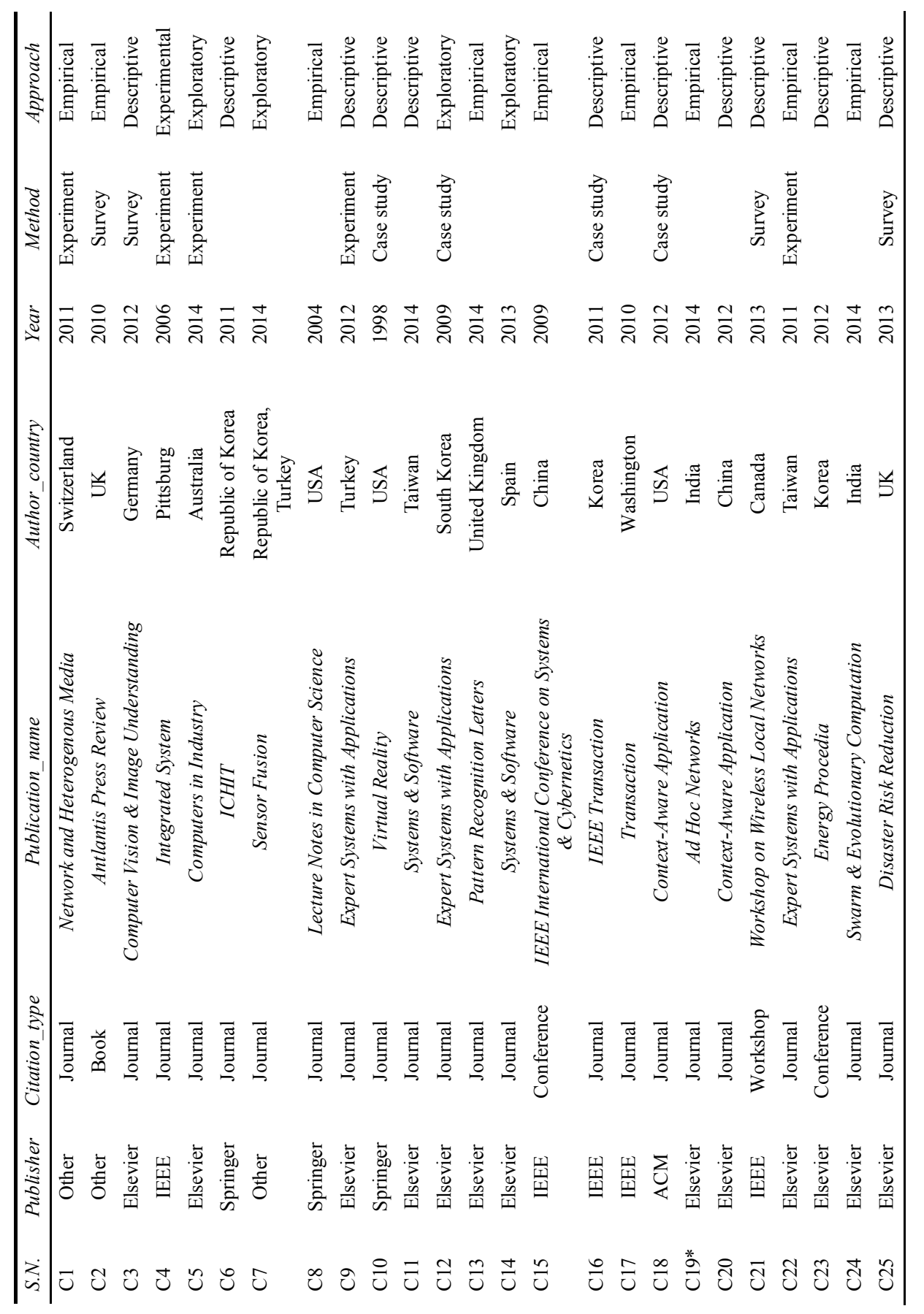


Table 3 Study dataset (continued)

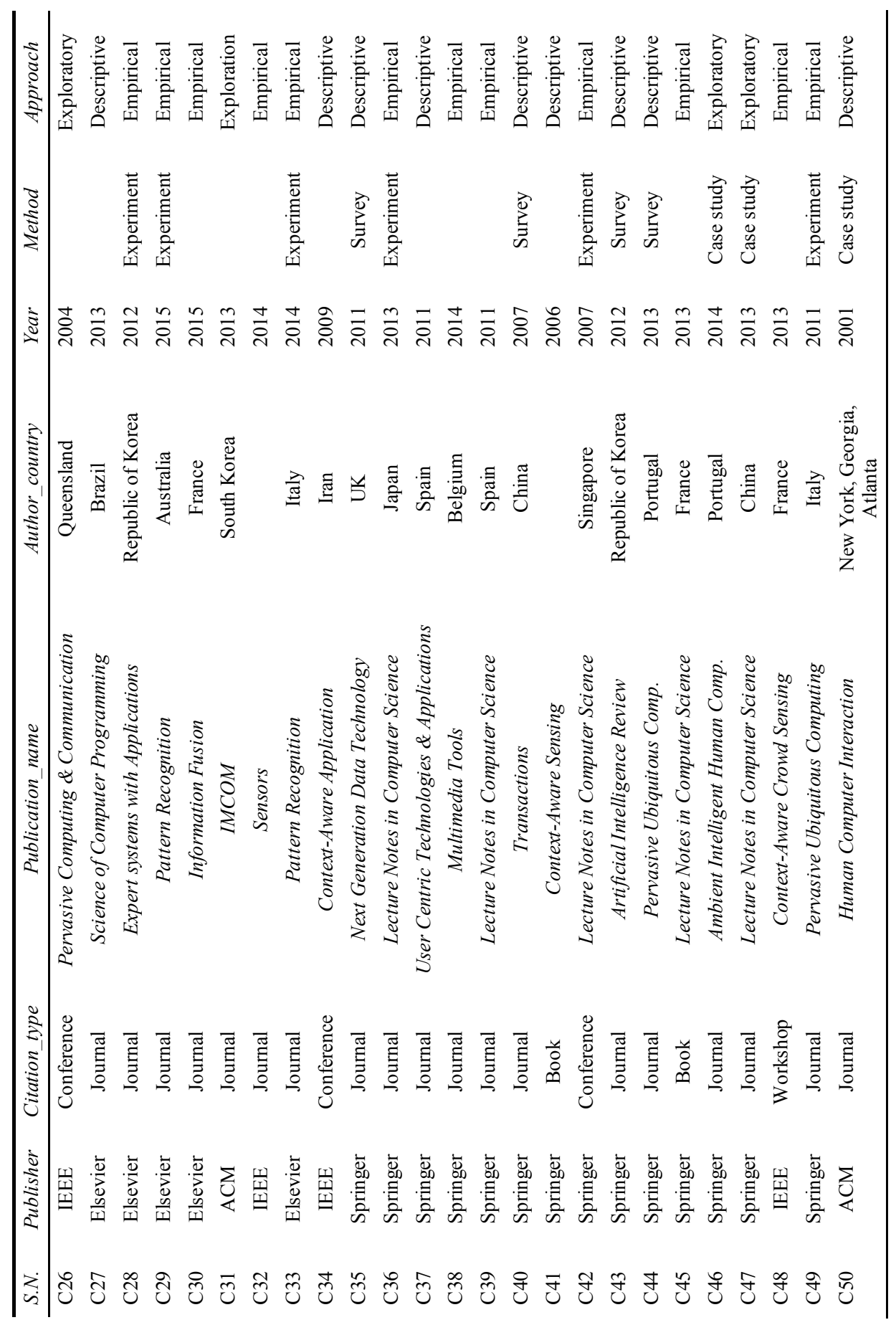


Table 3 Study dataset (continued)

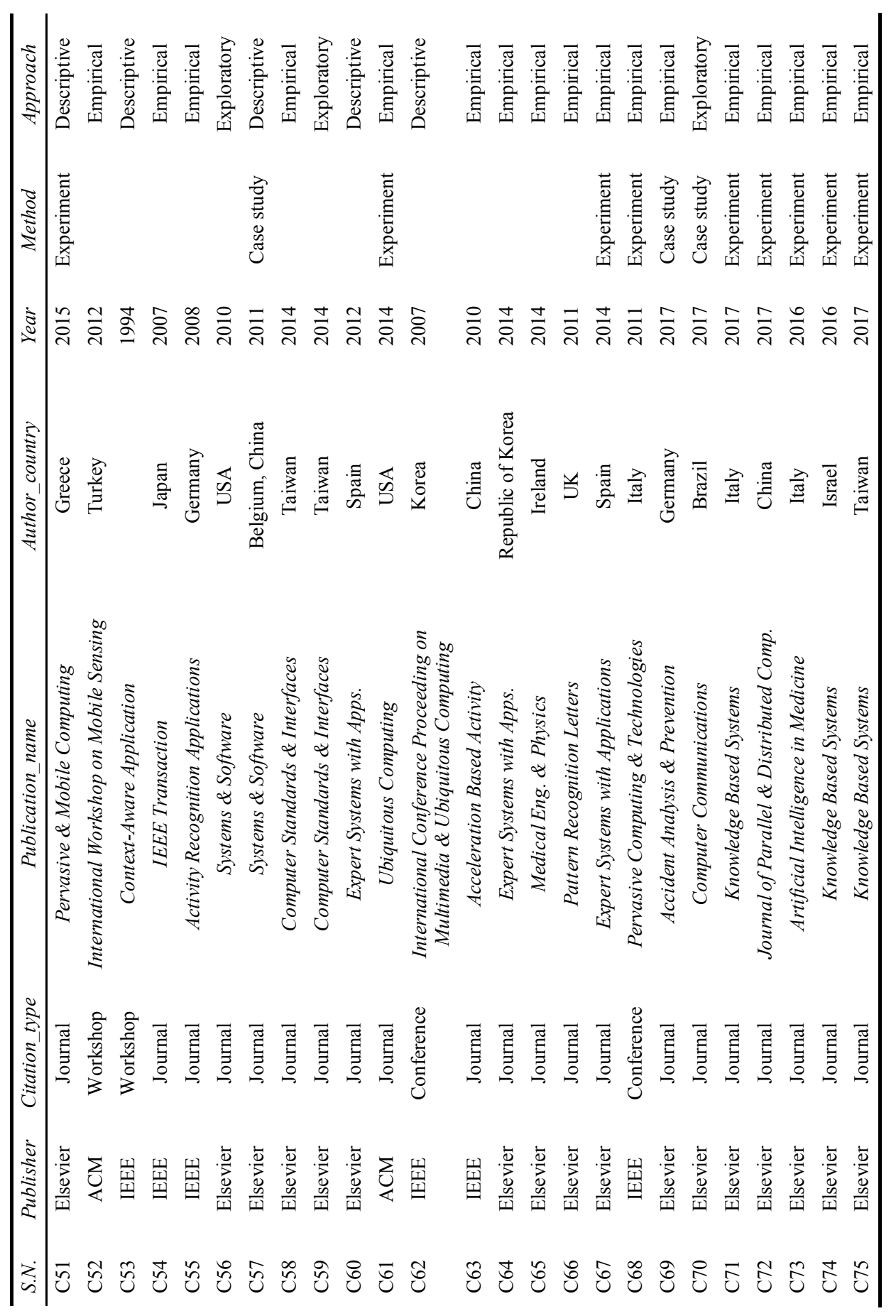


According to Wohlin et al. (2012), three different methods for empirical investigation are used to evaluate new techniques, methods and tools. The investigation includes types of experiments, surveys and case studies. Experiments are criteria for exploring the relationships such as identifying the correlation between two variables. Surveys are suitable forms of investigation when the method of study is in use for a while. While case studies are used for similar situations like that of experiments, but in this aspect they are observational studies (Wohlin et al., 2012; Kitchenham et al., 1995). The empirical validation types identify for papers listed in Table 3 are summarise in Table 4. A similar empirical classification used in Dybå and Dingsøyr (2008) were adopted where a relevant concept in the domain is considered.

Table 4 Empirical methods in the selected study

\begin{tabular}{ll}
\hline Empirical method & \multicolumn{1}{c}{ Explanation } \\
\hline Case study & $\begin{array}{l}\text { A situation where-by sets of people are asked to perform certain tasks in a } \\
\text { controlled environment is an experiment. In the end, results are generated } \\
\text { from inspecting the task outcome. }\end{array}$ \\
Experiment & $\begin{array}{l}\text { Sets of people are used to participate in questionnaire filling directly or } \\
\text { indirectly at times it may be through the internet. } \\
\text { Survey }\end{array}$ \\
$\begin{array}{l}\text { Results are derived from the valid answer supplied by respondents to the } \\
\text { questionnaires. }\end{array}$
\end{tabular}

Source: Ampatzoglou and Stamelos (2010)

\subsubsection{Data analysis}

The data collection specified in Section 2.3 and summarised in Table 3 are statistically analysed to investigate the following:

- The number of publications (primary studies) showing techniques used as published per year addresses Q1.

- The number of researches each country and continent produced in the last 12 years also addressed Q1.

- The strength and weaknesses of the identified techniques concerning approaches used in CA AR researches that investigates DM specifically addresses Q2.

- The number of studies that shows contributions mapped into research focuses and types is addressed in Q3

- The number of studies that employed each research approach related to disaster issues with their methods addresses Q4.

In Figure 4, the data analysis was conducted based on the selected primary studies. From the study, 2014 had 16, as the highest publications, 2017 has five and the lowest is 2008 having one. Most of the reviewed papers were on context-awareness and activity recognition (CAR) but only a few of them addressed issues in crowd disasters, while some discussed other disaster issues. The reason for context-awareness was because many fields are faced with the issues of context acquisition, sensing and modelling. Most importantly, the emergence and penetration of smart mobile devices has given rise to the 
development of CA system which utilises sensors to collect relevant data about users to improve different users services (Unger et al., 2016). Similarly, contextual information has equally influenced building of systems to meet users' needs more efficiently and practically (Lee et al., 2017). In addition, the reasons highlighted, by Unger et al. (2016); Lee et al. (2017), CA is applicable to many other domains including adaptation of human robot behaviour by Nessi et al. (2016) and the prevention of road accident through Vehicle safety actuators by Böhmländer et al. (2017). The use of CA application and its techniques has been a hot research area in recent time meanwhile, the research is still growing.

Figure 4 Number of selected primary studies by year of publications (see online version for colours)

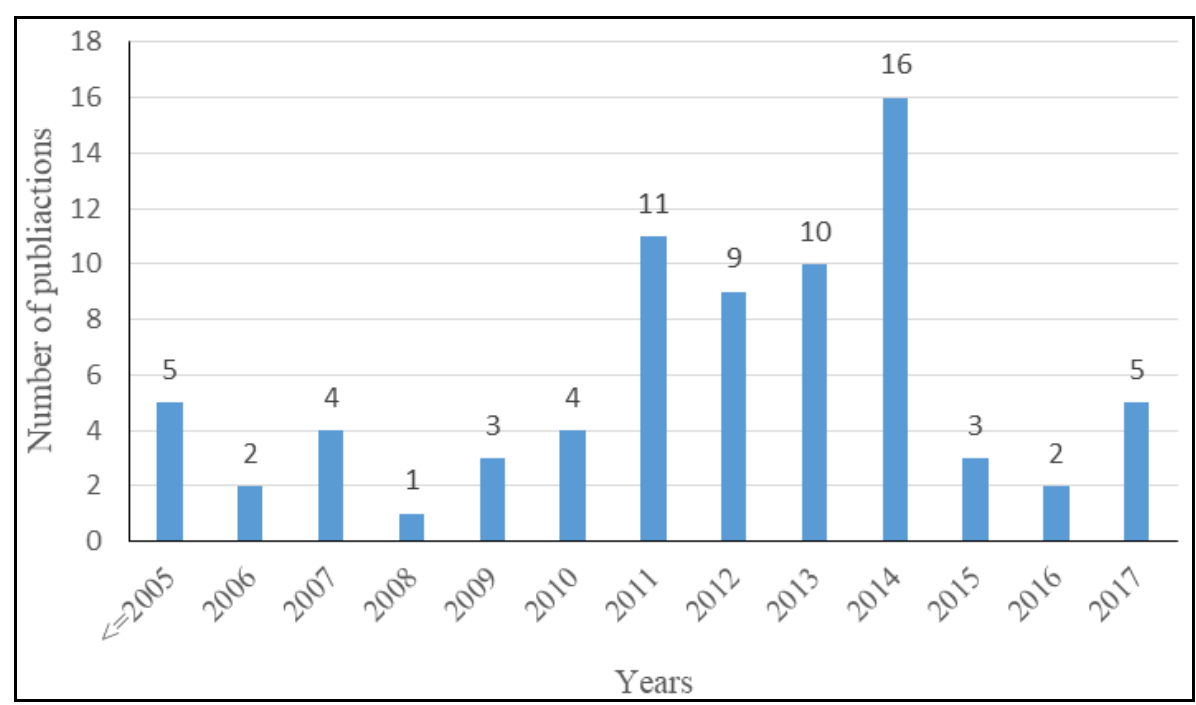

\section{Results}

This section presents the results of statistical analysis using the dataset of the primary studies shown in Table 3. It is important to state that description of context-interaction issues using AR accompanied with the discussion of RQs in Section 2 are described in this section:

Q1 What are the extent of CA research that is related to AR?

Q2 What are the strength and weaknesses of the existing context-awareness techniques with AR?

Q3 What are the contributions in context-awareness with AR related to DM?

Q4 Which of those context-awareness with AR researches addresses issues on crowd disasters? 
Context-awareness is a field that promotes pervasive computing research through the use of smartphone device with the aid of inbuilt sensors. Context-awareness has been found to be useful in crowd monitoring and other disaster-related domain such as vehicle safety on the roads due to its ability to offers feedback using context-awareness when programmed with sensors on mobile Android applications (Böhmländer et al., 2017; Ramesh et al., 2014). Figure 4 earlier presents the number of selected publications by years from 2005 up to 2017 based on research domain under review as stated in Section 2. Figure 4, also provides information on the number of articles recorded by each type of publication. Specifically, journal, conference, workshop and book chapters as shown in Table 5. The years of publication considered are between 1994 to 2017, but articles that belong to 1994-2004 are recorded as $(<=2005)$ using the primary studies as showed in Table 3. The most active research publication channels for CAR studies distribution published based on publishers name are ScienceDirect popularly known as Elsevier journals with 35 (46.7\%), Springer 17 (22.7\%), IEEE 15 (20.0\%), ACM $5(6.7 \%)$ and Google scholar $3(4.0 \%)$ as shown in Table 5. However, 75 primary studies were identified during the search processes. Out of the 75, 60 were journal articles, eight were conference papers, four were workshop papers and three were contributions from book chapters. Research related to CA and DM was just three publications. This section describes the results of the studies based on the RQs formulated. Table 3, Figures 4 and 5 form the basis of discussions for RQs Q1-Q4.

Table 5 Number of publications per publisher

\begin{tabular}{lcc}
\hline Publisher name & \#Publications & Percentage (\%) \\
\hline ScienceDirect & 35 & 46.7 \\
Springer & 17 & 22.7 \\
IEEE & 15 & 20.0 \\
ACM & 5 & 6.6 \\
Google scholar & 3 & 4.0 \\
\hline
\end{tabular}

\section{Discussions of results}

To address Q1, Figure 5 presents the number of research activities by country of the research based on the corresponding author's name within the periods of 12 years using the details in Figure 4 and primary studies presented in Table 3.

Details of published papers are showed in Figure 4 and countries of research activities by authors are presented in Figure 5. Analysis in Table 6 addresses the RQ Q2, it revealed that 35 techniques were reported in this study from 1994 to 2017. The 35 techniques identified are shown in Table 6 alongside with their strengths, weaknesses and sources base on the SLR analysis. The outstanding research gaps from this study summarised in Figure 6(b), where less attention was paid to metric contribution, architecture and model. Although, many researches have been done on the framework, but less numbers of research were found on DM. Further research initiative in a crowd monitoring using AR is still possible (Abowd et al., 1998). 
Table 6 Existing context-awareness techniques, strengths and weaknesses

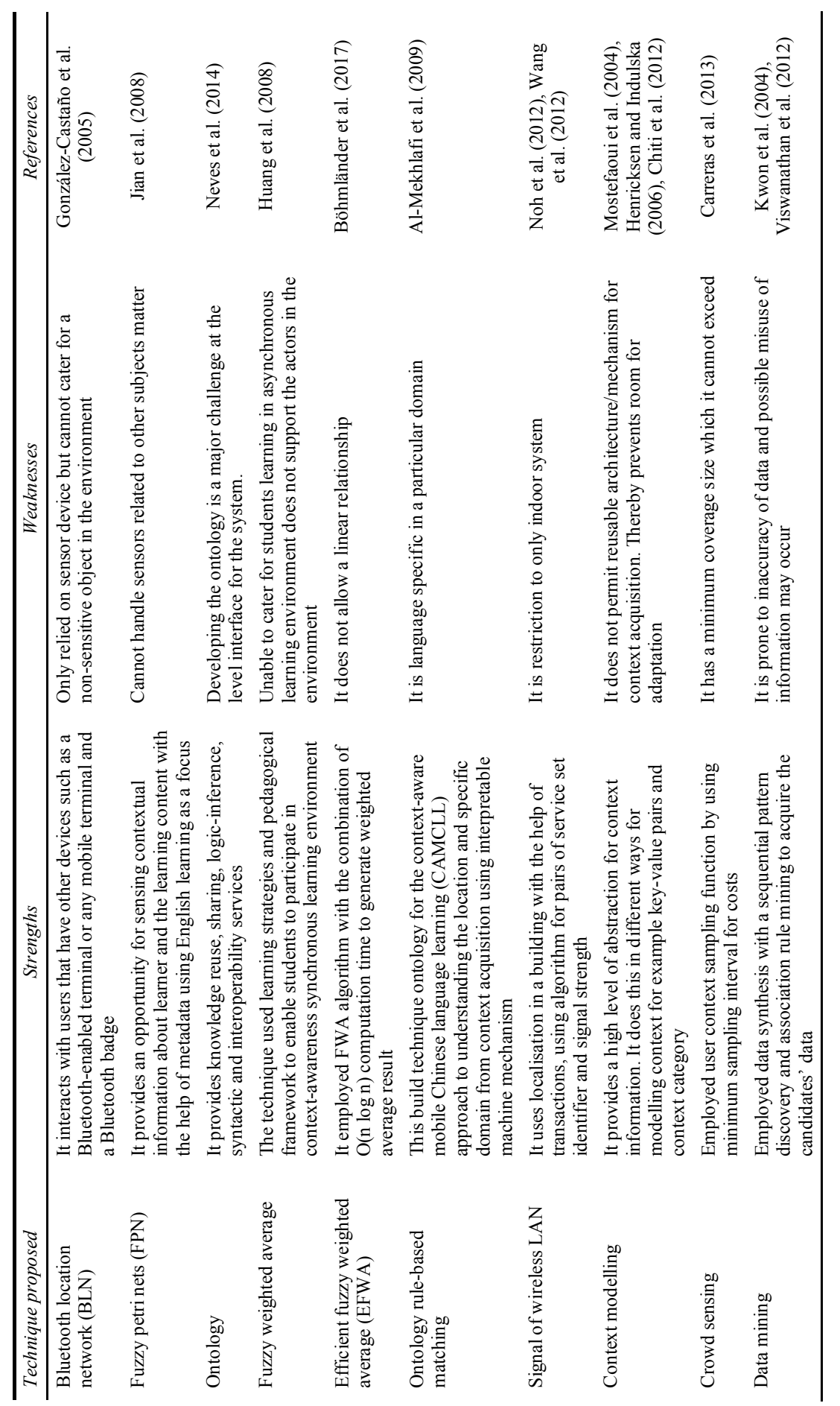


Table 6 Existing context-awareness techniques, strengths and weaknesses (continued)

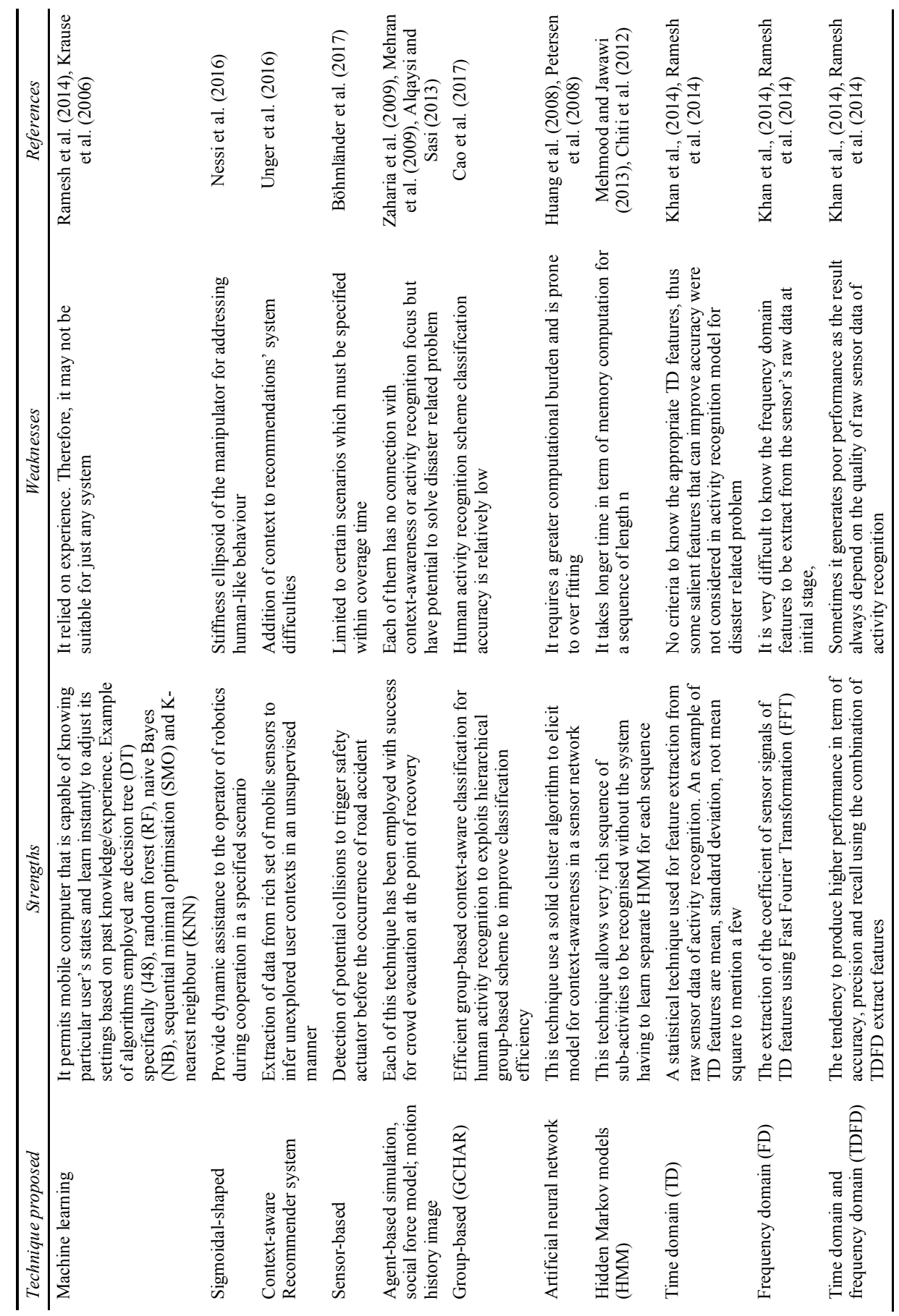


Table 6 Existing context-awareness techniques, strengths and weaknesses (continued)

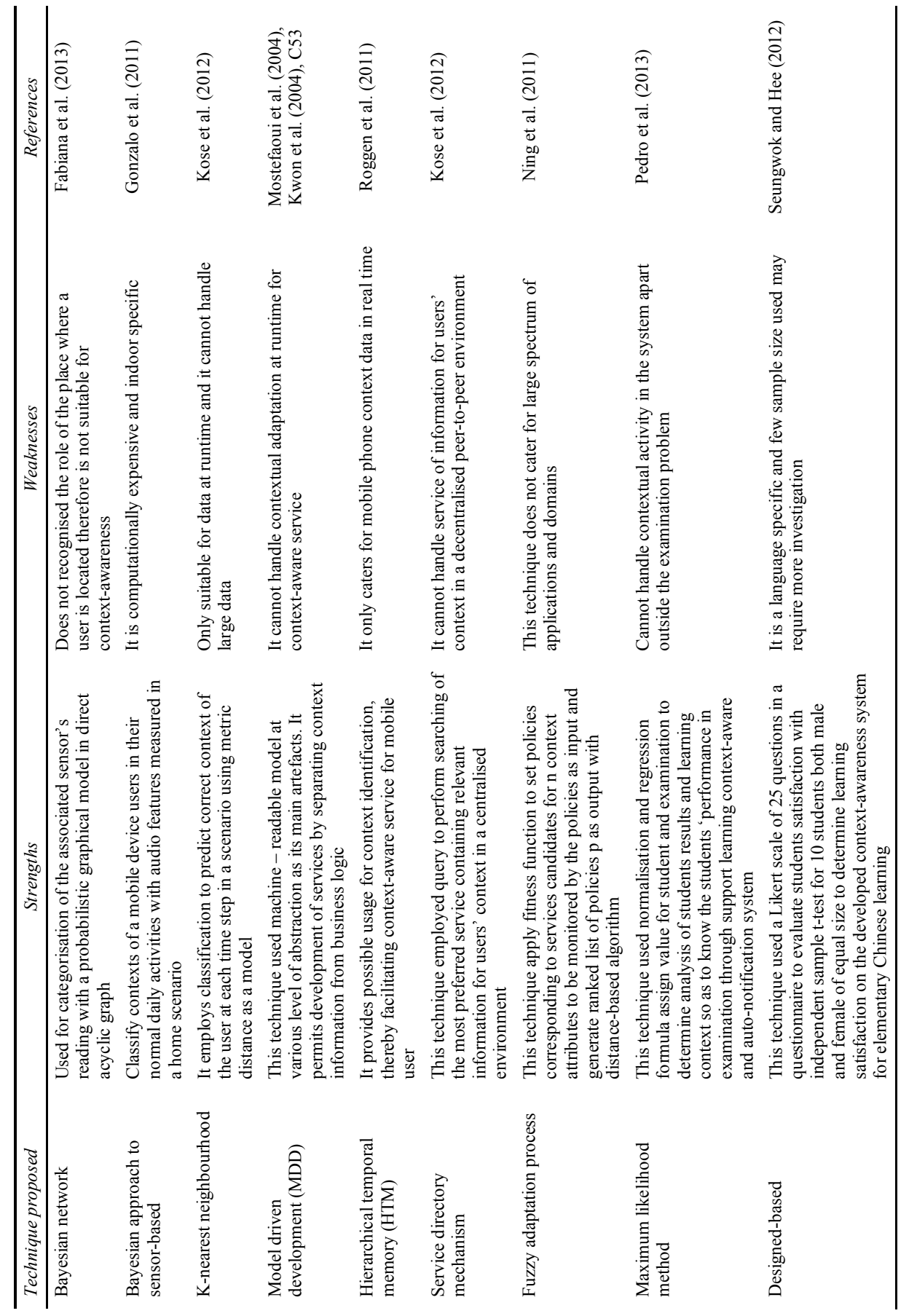


Table 6 Existing context-awareness techniques, strengths and weaknesses (continued)

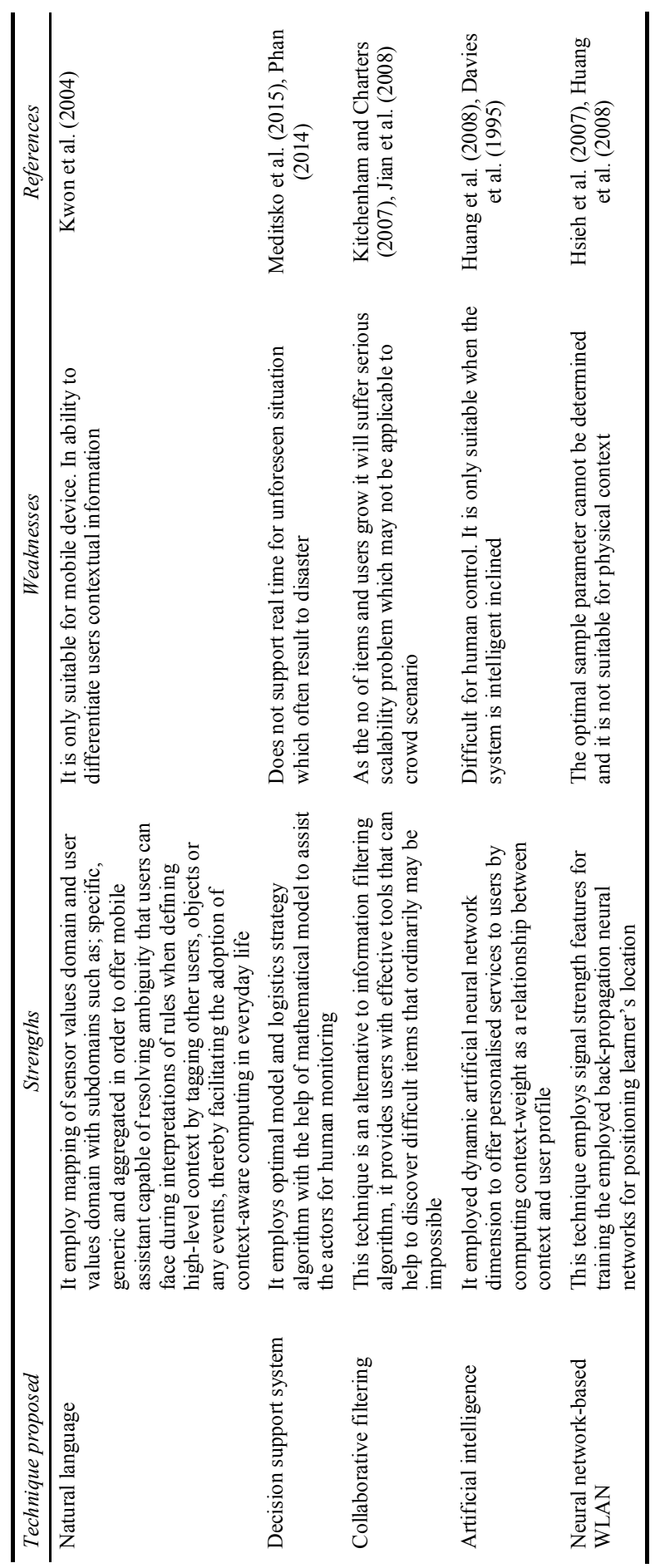


Figure 5 Research activities by authors' country name (see online version for colours)

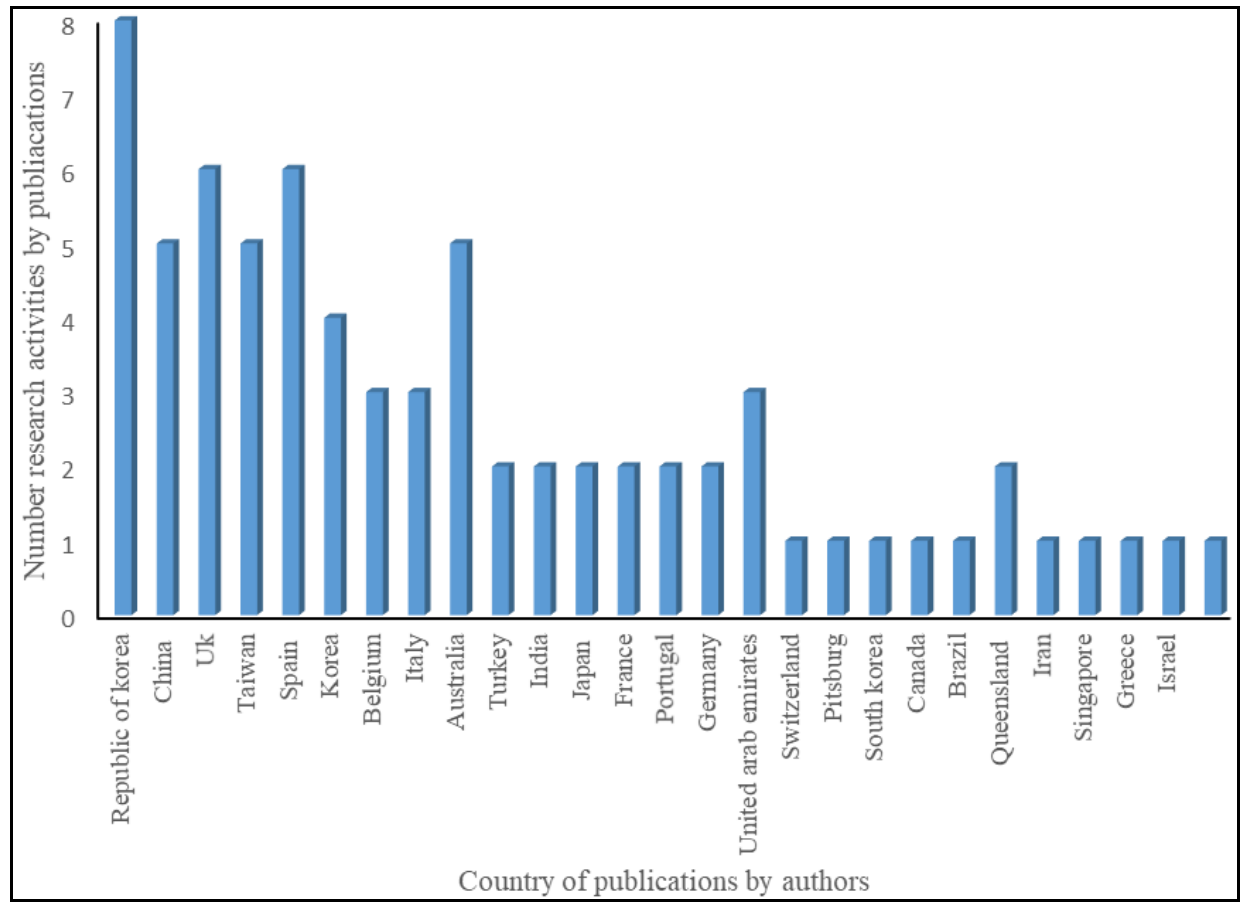

\subsection{Trends in context-awareness techniques using $R Q 2$}

It is very rare, to see disciplines and industries where CA related applications are not applicable, as a result of context and its relationships with environmental and situational changes in our daily life. This statement support previous research in the literature from Schilit et al. (1994), Schmidt (2013) and Ramesh et al. (2014) with explanations provided for context and the origin of 'CAC' as proposed in Ampatzoglou and Stamelos (2010) also cited in Wohlin et al. (2012). Several concepts has been proposed in the area such as education (Glass et al., 2002; Kitchenham et al., 1995), building automation (Dybå and Dingsøyr, 2008), healthcare (Unger et al., 2016), library management (Lee et al., 2017), movie industry (Nessi et al., 2016), business (Böhmländer et al., 2017), restaurant (Ramesh et al., 2014) and banking institution (González-Castaño et al., 2005) to mention just a few. Several techniques have been proposed for context-awareness related research either for services or applications-based research. The techniques include collaborative filtering (Jian et al., 2008), FPNs (Neves et al., 2014), artificial intelligence (Huang et al., 2008), ontology for contextual entity description (Glass et al., 2002; Al-Mekhlafi et al., 2009) and activity-based entity relationship (Noh et al., 2012). In addition to Glass et al. (2002), Jian et al. (2008), Neves et al. (2014), Huang et al. (2008), Al-Mekhlafi et al. (2009) and Noh et al., (2012), 27 additional techniques have been identified from literatures as part of methods that can be use when undergoing research using context-awareness computing, making a total of 35 techniques reported in this study from 1994 to 2017. The SLR conducted in this study, will further provide evidence in this research domain to know what has happened over the years, and beyond 2000-2007 as 
presented in Kitchenham and Charters (2007) to date. Also, in Wohlin et al. (2012) and Wang et al. (2012), though both of them (Wohlin et al., 2012; Wang et al., 2012) did not indicate the years of coverage in their studies. The topics of concerns investigated are; CAC research with 'context-aware systems'; 'CMPMFs' and 'context-awareness in healthcare'. Though, the literature review presented in the previous study, are more general since they focused on how to identify the likely applications areas which existing studies have covered in one of the RQ employed in Section 2. However, this study is the first to specifically focus on SLR for disaster related problems using AR based on context-awareness. We are not aware of an existing SLR study in this domain from the literatures. Disaster management is everybody business in our society. Therefore, current research on DM is very essential to minimise risk in human lives to impact the growth and development of any nation through the safety of human lives and properties.

Research in the area of disaster management has grown rapidly over the years. However, most researchers have concentrated efforts on techniques such as agent-based simulation (Zaharia et al. 2009); social force model (Mehran et al., 2009); motion history image on crowd evacuation (Alqaysi and Sasi, 2013), for a reason, knew to them and the fact that favourable outcome was obtained from these techniques. The three techniques; agent-based simulation (Zaharia et al. 2009); social force model (Mehran et al., 2009); and motion history image (Alqaysi and Sasi, 2013) does not focused on the utilisation of sensor's data using AR from mobile phone sensing (MPS) and context-awareness for mitigation of crowd disaster in their research.

Most importantly new trend of research on CA was remarked in Ramesh et al. (2014) as "the critical consideration of their research on context-aware computing and wireless sensor network (CAC-WSN) to improve the quality and reliability of sensing information by utilising the potential of CAC." In Aloulou et al. (2015), it was stated that any decision make using CA systems are very crucial and have a meaningful impact on the users, as a result, context-awareness technique can help to realise accurate decision needs for monitoring real life situations in a crowd, during emergency to minimise risk and prevents danger pose to human lives. Therefore, as observed in Charith Perera et al. (2015), the benefits of the proposed solution with AR and context-awareness but not limited include the following:

1 the ability of people to get relevant information according to their need using CAC

2 sensors learns about human being through context

3 context is used for real-time decision support and activity, which has helped the smartphone to become smarter.

4 the future holds lots of promises for CA applications.

\subsubsection{Context-related information that has been used for DM}

Time domain (TD) is a feature extraction method conventionally used in AR research domain (Ramesh et al., 2014; Khan et al., 2014; Kawarehara et al., 2007). Example mean, standard deviation, (STD), minimum (min.), maximum (max.), range, variance, root mean square (RMS) and interquarter tile in Table 6, the TD features that has been extracted and used for AR specifically for prediction of crowd disaster are mean along $\mathrm{x}, \mathrm{y}, \mathrm{z}$ axes; STD along $\mathrm{x}, \mathrm{y}, \mathrm{z}$ axes; correlation coefficient (COR) of $\mathrm{xy}, \mathrm{xz}, \mathrm{yz}$ axes; 
RMS of $x, y$ and $z$ axes (Ramesh et al., 2014). In addition to this, the frequency domain (FD) for RMS has equally been used. Consequently, the TD and FD metrics (mean, STD, COR, RMS and FFT_RMS) have produced good result in AR research (Helbing et al., 2007), outside their commonly used as feature extraction methods in the AR domain (Khan et al., 2014; Guiry et al., 2014). The features are of light weight in nature this potential makes the features suitable for smartphone with average memory size and processing speed. Therefore, the features require less battery consumption of smartphone device when used to monitor movement behaviour of people in a crowd scenario. Most importantly, some salient features capable of producing higher accuracy for early detection of danger using AR in a crowd, but shows good result in other domain not considered in the previous disaster domain research are among the challenges that this SLR equally identified as part of finding.

\subsection{Focus of the research}

The selected studies were divided into five research focus as shown in Figure 6(a) based on the research topics considered in this paper. The keywording method described in software engineering (Petersen et al., 2008) in combination with Mehmood and Jawawi (2013) were studied and apply to the research domain under consideration in line with issues, relevant area and problems. The problems include application, context acquisition, sensing, and modelling (context interaction), AR prediction, context reasoning and DM.

\subsubsection{Application}

This category mainly included papers that report facts about applying the concept in practice. For instance, papers that present model or method using existing approaches or proposal to develop a system or prototype applied to a specific scenario. These are found in nearly all literature but we only concentrate on those publications related to topic that focuses on problem of interest.

\subsubsection{Context acquisition, sensing and modelling (context interaction)}

The context acquisition, sensing and modelling are pertinent issues associated with context-awareness application referred to as context interaction. This includes studies that describe a novel method or model and any of those papers which propose a solution or contribute accordingly by addressing either of these issues in their research paper.

\subsubsection{Activity recognition accuracy prediction}

Activity recognition accuracy (ARAC) prediction includes data analysis research papers. The papers focused on a novel method, model, architecture or framework in human activity monitoring. They use classification algorithms in carrying out their data analysis mostly to determine ARAC.

\subsubsection{Context reasoning}

The context reasoning is papers that focused on novel method, model and having elements of clever technique such as artificial intelligence (Tuan et al., 2012), ontology 
(Fernandez-Caballero et al., 2012). We identify some ontology-based study in connection with AR and statistical inference.

\subsubsection{Disaster mitigation}

This category of papers propose a unique model and utilised existing methods while other authors contribute frameworks (Abowd et al., 1998) by addressing problems relating to crowd and stampede (Ramesh et al., 2014) detection using the topic of concern in this study area. Figure 6(a) suggests that few of the selected primary studies from the entire publications addressed issues of DM based on crowd scenario and other related disaster control which are $4(4 \%)$ of all the 75 publications found useful in this SLR. The summary of the analysis explained in Sections 5.1.1-5.1.5 depicts Figure 6(a).

Figure 6 (a) Research focus (b) Research contributions (c) Research types (d) Mapping flow of the research contributions and types based on the research focuses on the study (see online version for colours)

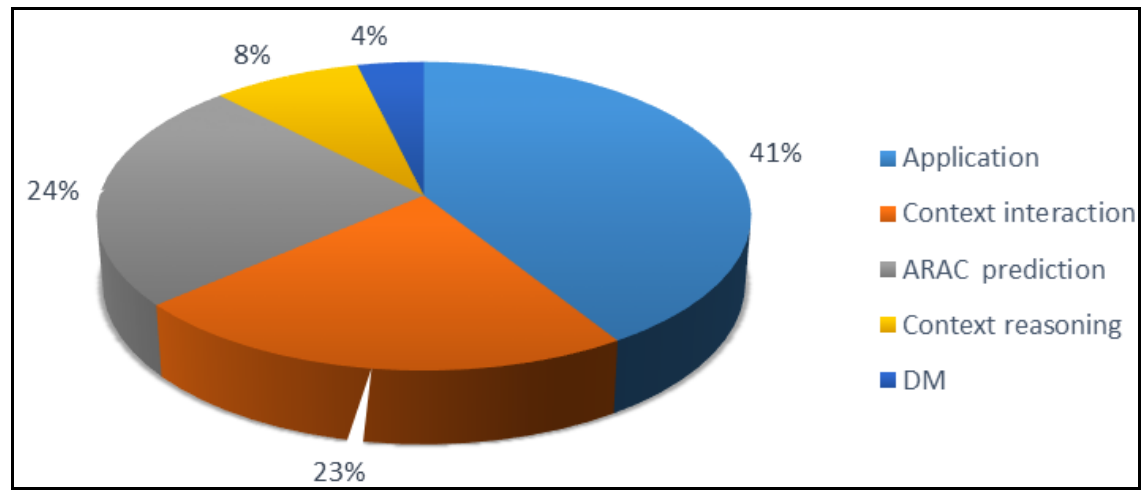

(a)

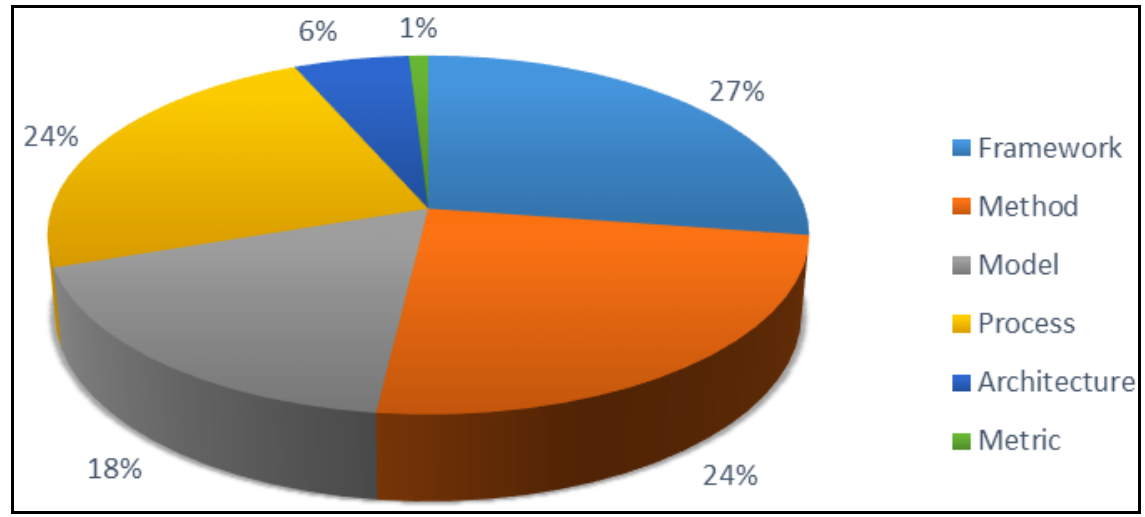

(b) 
Figure 6 (a) Research focus (b) Research contributions (c) Research types (d) Mapping flow of the research contributions and types based on the research focuses on the study (continued) (see online version for colours)

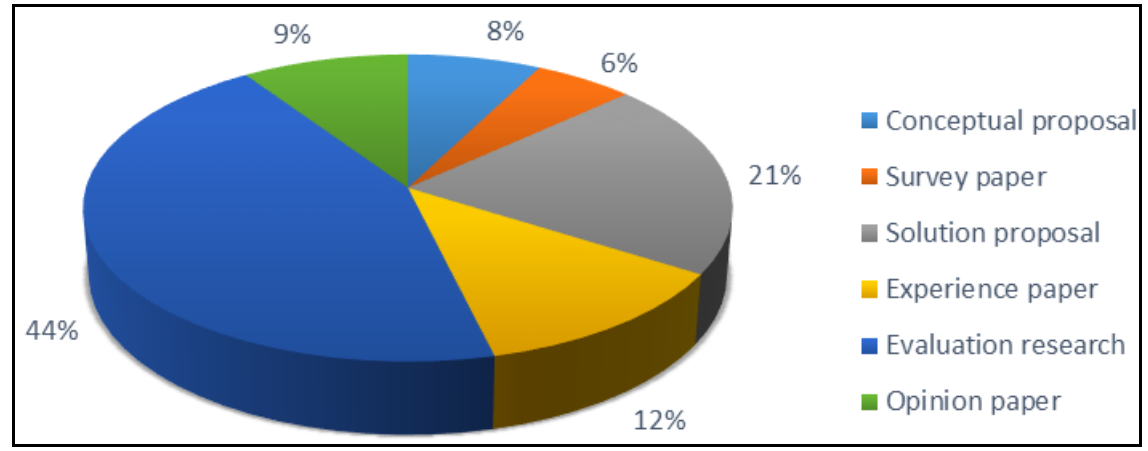

(c)

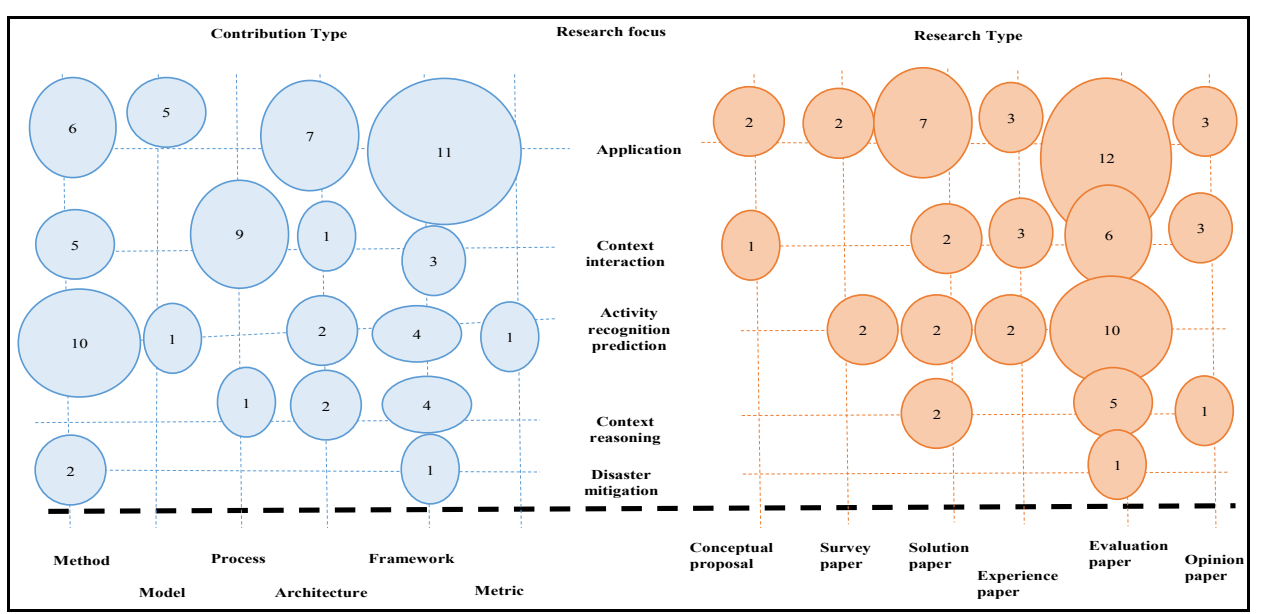

(d)

\subsection{Research contribution type (Q3)}

This section provides answer to the Q3 as highlighted in Section 2.3.2. It is divided into six different categories and they are described in Section 5.2.1. Part of them appear as the title of the paper identified as a primary selected study.

\subsubsection{Method}

This describes contribution that specifically provides a novel method or improved approach or a specific way of how context can be composed or adapted for CA about human activity recognition (HAR). It is used while addressing some of the research focus. 


\subsubsection{Model}

It describes contributions that present a conceptual discussion or comparative study, explore relationships, identify challenges, types of classification for CA and AR related topic.

\subsubsection{Process}

They are papers that extend the CA modelling or approaches and provide a detailed discussion on the overall CA system development process. For example, a paper that presents an abstraction used to describe context interaction of users and the behaviour of people in an environment.

\subsubsection{Architecture}

It describes contribution that focus on architecture support for CA research and AR either in the form of design building or structure that can be integrated into a framework.

\subsubsection{Framework}

It refers to a basic conceptual structure or description of a process that constitutes a complex task in a contextual relation form. It is explained in a model form or predefined diagram that addresses $\mathrm{CA}$ and $\mathrm{AR}$ scenario.

\subsubsection{Metric}

This set of papers describes contributions related to preprocessing and general form of metrics that is use when dealing with context recognition and related research activity. For example different standard techniques are discussed in the paper. The summary of the analysis explained in Sections 5.2.1-5.2.6 depicts Figure 6(b).

\subsection{Research type}

The research type presents the kinds of research done in the primary study. We employed the scheme proposed by Weiringa et al., (2006) and that of Mehmood and Jawawi (2013) for the classification of research type. Descriptions of research type identified in the primary study are classified through Sections 5.3.1-5.3.6.

\subsubsection{Conceptual}

The papers that focused on things that is in existence in a unique way. They did not solve the problem but proposed a theoretical framework that may include some form of enhancement by adding a new characteristic.

\subsubsection{Experience}

This kind of paper reports on personal knowledge revealing past ordeals in their real life project. It usually presents details on how the project was accomplished, as well as how it was done for publication. 


\subsubsection{Evaluation}

This type of paper tries to examine a solution that has been applied practically. Such papers normally explore the practical implementation of solutions and come up with results using case studies or field studies.

\subsubsection{Solution}

This provides a solution to any problem mentioned or described in the paper. It is achieved by contributing a novelty result through technique or model.

\subsubsection{Survey}

These papers deal with a general view of any research topic, in general, form (in-depth). It is regarded as an investigation of what other researchers have done in a particular domain identify the problem and profer solution. In this case, we focus on CA and AR related topics with emphasis on DM.

\subsubsection{Opinion}

This type of paper reports on a personal view of the author on true satisfaction or dissatisfaction on a specific method, or technique. Such papers present their view or feelings on how certain technique(s) should be realised. For the purpose of RQ Q4. Figure 6(a) provides answers to the Q4, four (4\%) addressed issues related to DM in a crowd out of all the 75 selected primary studies, Ramesh et al. (2014); automatic video analysis of crowd disaster (Krausz and Bauckhage, 2012); and crowded surveillance scenes (Leach et al., 2014), though only Ramesh et al. (2014) proposed CA framework based on crowd abnormality monitor (CAM) and employed AR with machine learning approach to determine stampede occurrence. Ramesh et al. (2014) further remarked that higher ARAC is a necessity for effective and reliable stampede prediction in a crowded area. However, Cao et al. (2017) recently further remarked that HAR schemes classification accuracy is relatively low as well. Therefore, it is imperative to identify causes for the low accuracy and profer solution to improve the accuracy to prevent negative consequence the low accuracy can cause in a real life. Research types is summarised in Figure 6(c).

\section{Research activity on crowd DM issue (Q4)}

In Figure 6(a), few of the selected primary studies from the entire publications addressed crowd disaster issues and other related disaster control which is four $(4 \%)$ of all the 75 publications. This indication further explains why there is need for further research in the domain. Despite the overwhelming interest of researchers in CAC and AR, efforts in MPS for CAC with AR (Chao et al., 2010; Ramesh et al., 2014) is still very low. This prompted the recent development for the existing approach as earlier stated in Section 4.3.6. The distribution of other research focus showed in Figure 6(a) include, $44(41 \%), 26(24 \%), 24(23 \%)$ and nine (9\%) on application (Abowd et al., 1998; Kuo et al., 2014; Hong et al., 2009; Leach et al., 2014), ARAC, context interaction and 
context reasoning (Mehta and Banati, 2014; Gonzalo et al., 2011; Pozo et al., 2011; Lee et al., 2007) respectively. Meanwhile, stampede is a major cause of crowd disaster (Illiyas et al., 2013). According to Davies et al. (1995), search from media account and research results reported 215 human stampede identified worldwide, from 1980-2007 with over 7,067 deaths and over 14,000 injured. This pathetic situation influenced the interest of researchers worldwide in finding ways to reduce these lingering dangers in our society. Although risk from human natural hazards cannot be eliminated completely, rather it can be minimised through a systematic approaches using disaster risk reduction (DRR) (Gomez et al., 2009). This effort prompted the different methods, models, techniques and frameworks proposed in one study or the other using the technology under consideration. Consequently, the mapping of the research contributions and research types using the research main focus is summarised in Figure 6(d).

\subsection{Related crowd disaster researches}

Human stampedes is an hazards from mass gathering events and it has witnessed less attention worldwide while formulating risk management strategies (Illiyas et al., 2013). Research has shown that the mass gathering (crowd) originated from religious festivity (Illiyas et al., 2013). Crowd monitoring originated in 1995 when CCTV were used as means of monitoring human activities in a crowd with pattern recognition techniques (Davies et al., 1995). The technique which faced with the following short coming such as manually coordination, with lots human effort (tedious and cumbersome) above utilised physical appearance of security officers. These limitations led the proposed wireless sensor networks with wireless communication techniques for better situational awareness of monitoring people in crowded places (Gomez et al., 2009). However, it suffered from a high rate of false alarm, and the use of low power sensors in the study due to low temperature and acoustic sensors used makes the technique less reliable and undependable. The limitations of this study witnessed the introduction of an emerging technology with MPS by Roggen et al. (2011). Despite the novel contribution and solution proposed in Roggen et al. (2011), their approach suffers some weaknesses. Thus, the weakness and the stampede incident that claimed life of over 102 devotees in the State of Kerala in Southern India and the constant deaths of more than 100 people per year due to crowd disaster motivates the proposed CAC-WSN for a crowd DM by Ramesh et al. (2014). The study seeks to address HAR accuracy, poor real time information and high rate of false alarm for effective stampede prediction in order to mitigate crowd disasters as identified in Ramesh et al. (2014). However, Ramesh et al. (2014), was the first to introduce CA application using AR to investigate HAR accuracy as a basis for effective stampede prediction in mitigation of crowd disasters by developing multi-context-fusion which suffers some drawbacks led the study in this paper. CAness application availability on smartphone devices is a technology that helps to sensitise users of activities going on around them (Anguita et al., 2014). It has been used in prediction of web analytics (Kiseleva et al., 2013).

\subsubsection{Research gaps and recommendations for future research direction}

In Figure 6(b), the contributions from the primary studies shown in Table 3 shows that $29(27 \%)$ of all the publications are related to the framework. The distribution of the existing techniques, their strengths and weaknesses are summarised in Table 6. Less 
attention was paid to crowd disaster-related research with context-awareness applications and less emphasis is on context reasoning. Further research has the potential to provide efficient, accurate timeliness of sense information (ATSI) for the critical situation, reduce FNA; improve ARAC; utilisation of context information (SCI); and employing the use of MPS for reliable ARAC for stampede prediction in a crowd scenarios are discussed in Sections 6.1.1.1-6.1.1.6. The findings are summarised as follows: in Figure 6(a), less attention was paid to crowd disaster related research with CA application and context reasoning. Figure 6(b) showed that less attention is equally paid to metric contribution, architecture and model. Though many approaches have been reported on framework, only few study focuses on DM.

\subsubsection{Accurate and timeliness of sensed information}

ATSI for critical situations is important to react to human safety in real time (Ramesh et al., 2014). Figure 6 indicates that only one of the selected studies takes cognisance of this important issue of human safety in literature. Also, Fruin (1993) identified the importance of time and information as a critical factor responsible for the causes of stampede in any crowded area in its paper titled 'Causes and prevention of crowd disaster' where he proposed the first model to described stampede accident. Based on the first model, one can deduce the fact that any CA framework with the suggested characteristics can adequately support a risk reduction for stampede occurrence to prevent crowd disaster in a crowded area. The solution in previous research on Muslim pilgrimage in Hall et al. (2009), Helbing and Mukerji (2012) and Luštrek and Kaluža (2009), once led to structural alternation and re-arrangement of the pilgrimage, which prevented deadly occurrence of stampede during the Moitinho de Almeida (2016) and Ramesh et al. (2014) study, is a welcome development that needs continuation of such research to meet up with the present dynamic and technological advancement using novel approach.

\subsubsection{FNA for effective mitigation of crowd disaster}

FNA can be determine by false negative rate (FNR). FNR is one of the common measurements in a classification evaluation in AR and data mining research (Gomez et al., 2009). FNR is the number of misclassified negative activity meant to be accurate but predicted wrongly in any classification analysis (Ramesh et al., 2014; Alvarez de la Conception et al., 2014). Investigation of event prediction before any terrible accident happen is very important (Fradi and Dugelay, 2015). Although, it is applicable to classification evaluation but is very relevant when we talk of detection of abnormal movement in a crowd scenario as well. To the best of the researcher's knowledge only four studies related to crowd monitoring found in literature are shown in Figure 6(a) (Ramesh et al., 2014; Roggen et al., 2011). Most importantly one of the study employed feature extraction method using raw sensor data from AR for the prediction of crowd disaster based on ARAC performance (Ramesh et al., 2014). However, major limitation of existing study is high FNA noticed in Ramesh et al. (2014), which is attributed to the ARAC of $92 \%$ reported. The ARAC is inadequate for stampede prediction during emergency in a crowd scenario. As a result of the high FNA, there is needed to extend the research conducted by Ramesh et al. (2014), thus form the reason for the SLR conducted in this paper. For example, a case of someone who is almost fallen in a critical moment and such situation is reported to the security or stakeholder as sitting 
or standing require proper classification; the implication of this may lead to accident or pose a risk to human life if adequate attention is not taken, this scenario is trigger by FNA.

\subsubsection{Context interaction (sensing, acquisition, modelling)}

In Figure 6(a) context, interaction showed 13 publications from the selected primary studies that dealt with important issues in CA application. These are challenging issues as far as CA researches are concern (Musumba and Nyongesa, 2013; Guiry et al., 2014). In addition, Ramesh et al. (2014) addressed CA issue and profer solution for mitigation of crowd disaster using AR in a crowd scenario. In recent years, lots of considerable interest in context sensing for pervasive computing are conceived Bouguessa et al. (2015), meanwhile only few are used in disaster related problem. Likewise context acquisition, inference and modelling that affect people in the society was attempted to address crowd disaster in Ramesh et al. (2014). This is obvious because most researches in this domain often address similar issues related to users' environment, computing and communication. Irrespective of the domain either of the issues plays major role. Moreso crowd activity has direct relationship with human, lives while using mobile devices for service within the environment. It is therefore, important, for research in this domain to take care of how these issues can be incorporated to improve on the existing studies for effective AR monitoring using CA, in order to facilitate research and development for mitigation of crowd disaster.

\subsubsection{Investigation of ARAC}

- ARAC: It has been said that intelligent pervasive environments and applications will influence future and living spaces in transforming human lives and impact the society (Chen and Khalil, 2011). AR which is a classification problem is known as an increasingly important determinant to the success of $\mathrm{CA}$ and personalised pervasive applications (Roggen et al., 2011; Chao et al., 2010; Ramesh et al., 2014). In Figures 6(a)-6(b), some of the publications employed AR by collecting data in real time using different choice of number of participant (student) to investigate ARAC (Roggen et al., 2011; Chao et al., 2010; Ramesh et al., 2014; Meditsko et al., 2015). However, Ramesh et al. (2014) employs the AR using

20 participants to mitigate crowd disaster whenever an emergency is sensed thus predict at what time would stampede occur using CA framework with the CAC-WSN. Lots of researches in AR (Anguita et al., 2012; Kwon et al., 2014) were found in the literature but Ramesh et al. (2014) is the first to utilise the $92 \%$ of ARAC reported using DT (J48) specifically for mitigation of crowd disaster. Crowd disaster is an important global issue aimed to be address through SLR presented in this paper to X-ray the research gap and the unsolved problem in disaster management research. Crowd disaster is an issue in the previous study demands further investigation to further enhance the method of addressing the serious menace in human lives in our society. For example, online approach permits access to each data point of activity in real time with the adequate update AR data, which is capable of detecting abnormal behaviour that can lead to stampede in a crowd prior to the emergency occurrence. 


\subsubsection{Mobile phone sensing}

- MPS: Previous studies in crowd monitoring relied on video camera (Krausz Bauckhage, 2012); CCTV (Davies et al., 1995) and visual tracking (Sugimura et al., 2009). More than two billion people carry mobile phones (Fehske et al., 2011) which can easily help context-awareness application accessible to everyone. The ubiquitous devices with its increasing power of capturing, classifying and transmitting image, acoustic, location and other data, interactively or autonomously using adequate architecture, could act as sensor nodes and location-aware data collection instruments (Burke et al., 2006). The state-of-the-art study already emphasised the benefit of mobile phone integration with $\mathrm{CAC}$ as a necessity for making the devices capable of sensing the physical world, processing the current scenario, adapting and reacting to dynamic changes in the environment. However, the need to extend their research to explore the potential of MPS with AR to monitor people in a crowd. This MPS will aids reliable and effective prediction of crowd disaster in case of emergency (Ramesh et al., 2014).

\subsubsection{Feature extraction}

Over the years, feature extraction methods known as TDFD methods have shown good result in literature. Few authors who have conducted research using TDFD methods to extract features include (Ramesh et al., 2014; Luštrek and Kaluža, 2009) where they investigated 17 features comprises of mean, STD, correlation, SMA and entropy using support vector machine (SVM) for recognition performance. The such as (mean, STD, COR, RMS and FFT_RMS) were utilised and used in Ramesh et al. (2014). It features mentioned above. It is necessary for mean to be generated first before other statistical metric features can be extracted based on computed mean (Chen and Shen, 2017). The entire TD features were later transformed to FD using the FFT method.

\section{Context-related information not used earlier but newly suggested for DM}

Generally, the statistical techniques specifically TD are light weight features. However, there is no standard of lay down criteria for features to be extracted in AR and data mining research. Therefore, it is desirable to extract as many features as possible to generalise the model under review based on the problem focus. In this study, minimum (min), maximum (max), median, variance (var) and range along $\mathrm{x}, \mathrm{y}$ and $\mathrm{z}$ axes are suggested as reliable features has they have not been used before now in a disaster related issues especially for prediction of crowd disaster to minimise danger in an emergency. Furthermore, the newly suggested features are combined with (mean, STD, COR, RMS and FFT_RMS). As it is necessary for mean to be generated first before other statistical metric features can be extracted based on computed mean (Ramesh et al., 2014). The entire TD features were later transformed to FD using the FFT method. 


\subsection{Future research recommendation}

Further research initiative in a crowd monitoring using AR is still possible with enhanced feature extraction and feature selection using minimum redundancy maximum relevance technique and information gain. Because, the techniques listed above can be used to identify some salient features not considered as important in the previous DM research found in literature earlier mentioned in the paper. Further research has potential to provide efficient ATSI, and reduce FNA, improve ARAC with FNR, utilisation of context interaction to employ the use of MPS for better accuracy of stampede detection probability and prediction in Figure 7. Consequently, future research has potential to investigate AR for human stampede as an online approach (real time) instead of offline batch update, to address inaccuracy in AR and time complexity issues as matter of necessity in this 21 st century. Identifying TDFD features which has not been used in disaster domain but are capable of producing higher ARAC, recall, precision, f-score and FNR is desirable in this 21 st century and globalisation era.

Figure 7 SLR research gap findings between years 1994 to 2017 (see online version for colours)

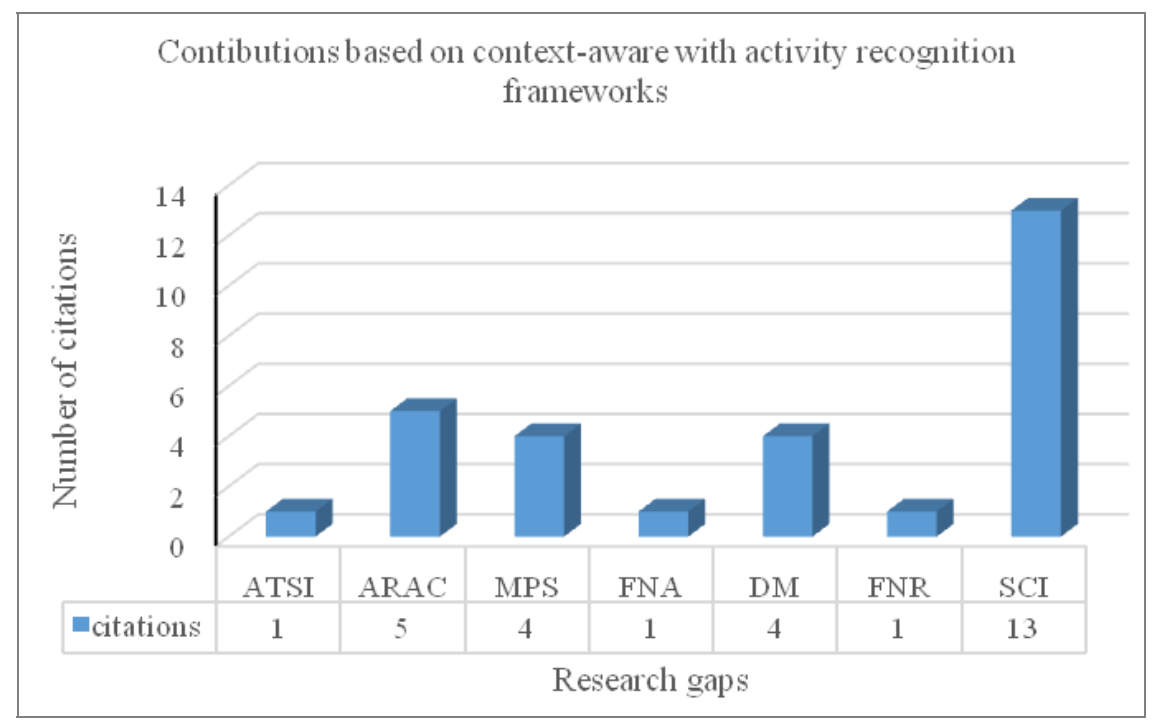

\subsection{Feature selection}

Feature selection is another relevant method which allows a dimensionality reduction of feature set numbers from the extracted feature in smartphone sensor data, used to monitor the individual activity of participant in a crowd. To avoid the high cost of computation, for the easy and fast decision process, the technique has a tendency to improve ARAC (Kandaswamy et al., 2013; Lin et al., 2015). The challenges are the problems discussed in Sections 6.1.1-6.1.1.6 which are results of SLR in Section 4 including the issue of inaccuracy in AR which has not been completely addressed. Examples of feature selection applied in AR are genetic algorithm, COR and information gain. However, 
developing valid classification (or prediction) model with feature selection is usually the key to success in most data mining, AR and pattern recognition problems (Kandaswamy et al., 2013; Lin et al., 2015).

\subsection{Conclusions}

The study revealed a great gap in DM, which is very important worldwide for safety control measure in a small or large gathering across the country where the crowd is inevitable. Future research has the potential to investigate AR for the prediction of crowd disaster to extend the CA framework to minimise risk and loss of human lives, and to promote growth and development worldwide with improve ARAC in real time for efficient mitigation of crowd disaster with suggested solution identified as findings in the study of a SLR presented in this paper.

\section{References}

Abowd, D., Dey, A.K., Orr, R. and Brotherton, J. (1998) 'Context-awareness in wearable and ubiquitous computing', Virtual Reality, Vol. 3, No. 3, pp.200-211.

Achimugu, P., Selamat, A., Ibrahim, R. and Mahrin, M.N.R. (2014) 'A systematic literature review of software requirements prioritization research', Information and Software Technology, Vol. 56, No. 6, pp.568-585.

Al-Bashayreh, M.G., Hashim, N.L. and Khorma, O.T. (2013) 'Context-aware mobile patient monitoring frameworks: a systematic review and research agenda', Journal of Software (1796217X), Vol. 8, No. 7, pp.1604-1612.

Al-Mekhlafi, K., Hu, X. and Zheng, Z. (2009) 'An approach to context-aware mobile Chinese language learning for foreign students', in Eighth International Conference on Mobile Business, 2009, ICMB 2009, pp.340-346.

Aloulou, H., Mokhtari, M., Tiberghien, T., Endelin, R. and Biswas, J. (2015) 'Uncertainty handling in semantic reasoning for accurate context understanding', Knowledge-Based Systems, Vol. 77, No. C, pp.16-28.

Alqaysi, H.H. and Sasi, S. (2013) 'Detection of abnormal behavior in dynamic crowded gatherings', Applied Imagery Pattern Recognition Workshop: Sensing for Control and Augmentation, 2013 IEEE, (AIPR), pp.1-6.

Ampatzoglou, A. and Stamelos, I. (2010) 'Software engineering research for computer games: a systematic review', Information and Software Technology, Vol. 52, No. 9, pp.888-901.

Anguita, D., Ghio, A., Oneto, L., Lianas Parra, F.X. and Reyes Ortiz, J.L. (2012) Human Activity Recognition on Smartphones for Mobile Context Awareness, pp.1-9, NIPS Workshop.

Böhmländer, D., Dirndorfer, T., Al-Bayatti, A.H. and Brandmeier, T. (2017) 'Context-aware system for pre-triggering irreversible vehicle safety actuators', Accident Analysis and Prevention, No. 103, pp.72-84.

Bouguessa, A., Mebarki, L.A. and Boudaa, B. (2015) 'Context-aware adaptation for sustaining disaster management', 12th International Symposium on Programming and Systems (ISPS), pp.1-10.

Burke, J., Estrin, D., Hansen, M., Parker, A., Ramanathan, N., Reddy, S. and Srivastava, M.B. (2006) 'Participatory sensing', WSW'06 at SenSys '06, 31 October, Boulder, Colorado, USA, ACM, pp.1-6.

Cao, L., Wang, Y., Zhang, B., Jin, Q. and Vasilakos, A.V. (2017) 'GCHAR: an efficient group-based context-aware human activity recognition on smartphone', J. Parallel Distrib. Comput. [online] https://doi.org/10.1016/j.jpdc.2017.05.007 (accessed 26 May 2017). 
Carreras, I., Miorandi, D., Tamilin, A., Ssebaggala, E.R. and Conci, N. (2013) 'Matador: mobile task detector for context-aware crowd-sensing campaigns', in 2013 IEEE International Conference on Pervasive Computing and Communications Workshops (PERCOM Workshops), pp.212-217.

Champiri, Z.D., Shahamiri, S.R. and Salim, S.S.B. (2015) 'A systematic review of scholar context-aware recommender systems', Expert Systems with Applications, Vol. 42, No. 3, pp.1743-1758.

Charith Perera, C.H.L., Srimaland, J. and Min, C. (2015) 'Context-aware computing in the internet of things: a survey on internet of things from industrial market perspective', IEEE Access Journal, Vol. 16, No. 1, pp.1-19.

Chen Y. and Shen, C. (2017) 'Performance analysis of smartphone - sensor behavior for human activity recognition', IEEE Transaction on Access Journal, Vol. 3, No. 2676168, pp.3095-3110.

Chen, H., Finin, T. and Joshi, A. (2003) 'An ontology for context-aware pervasive computing environments', The Knowledge Engineering Review, Vol. 18, No. 3, pp.197-207.

Chen, L. and Khalil, I. (2011) 'Activity recognition: approaches, practices and trends', Activity Recognition in Pervasive Intelligent Environments, 1st ed., Text book, Vol. 4, pp.1-31, Springer, Atlantis Press.

Chiti, F., Fantacci, R. and Mastandrea, R. (2012) 'A low complexity clustering approach enabling context awareness in sparse VANETs', in Global Communications Conference (GLOBECOM), 2012 IEEE, pp.61-66.

Davies, A.C., Yin, J.H. and Velastin, S.A. (1995) 'Crowd monitoring using image processing', Electronics \& Communication Engineering Journal, Vol. 7, No. 1, pp.37-47.

Davies, A.C., Yin, J.H. and Velastin, S.A. (1995) 'Crowd monitoring using image processing', Electronics \& Communication Engineering Journal, Vol. 7, No. 1, pp.37-47.

Docter, J., Licciardi, C.A. and Marchetti, M. (2007) 'The telecom industry and context awareness', in International Conference on the Management of Mobile Business, 2007, ICMB 2007, p.35.

Dybå, T. and Dingsøyr, T. (2008) 'Empirical studies of agile software development: a systematic review', Information and Software Technology, Vol. 50, Nos. 9-10, pp.833-859.

Fehske, A., Fettweis, G., Malmodin, J. and Biczok, G. (2011) 'The global footprint of mobile communications: the ecological and economic perspective', Communications Magazine, IEEE, Vol. 49, No. 8, pp.55-62.

Fruin, J.J. (1993) 'The causes and prevention of crowd disasters', Engineering for Crowd Safety, pp.99-108.

Glass, R.L., Vessey, I. and Ramesh, V. (2002) 'Research in software engineering: an analysis of the literature', Information and Software Technology, Vol. 44, No. 8, pp.491-506.

Gomez, L., Laube, A. and Ulmer, C. (2009) 'Secure sensor networks for public safety command and control system', in IEEE Conference on Technologies for Homeland Security, 2009, HST'09, pp.59-66.

González-Castaño, F.J., García-Reinoso, J., Gil-Castiñeira, F., Costa-Montenegro, E. and Pousada-Carballo, J.M. (2005) 'Bluetooth-assisted context-awareness in educational data networks', Computers \& Education, August, Vol. 45, No. 1, pp.105-121.

Hall, M., Frank, E., Holmes, G., Pfahringer, B., Reutemann, P. and Witten, I.H. (2009) 'The WEKA data mining software: an update', ACM SIGKDD Explorations Newsletter, Vol. 11, No. 1, pp.10-18.

Helbing, D. and Mukerji, P. (2012) 'Crowd disasters as systemic failures: analysis of the love parade disaster', EPJ Data Science, Vol. 1, No. 7, pp.1-40.

Helbing, D., Johansson, A. and Al-Abideen, H.Z. (2007) 'Dynamics of crowd disasters: an empirical study', Physical Review E, Vol. 75, No. 2007, p.046109.

Henricksen, K. and Indulska, J. (2006) 'Developing context-aware pervasive computing applications: models and approach', Pervasive and Mobile Computing, Vol. 2, No. 1, pp.37-64. 
Hong, J-y., Suh, E-h. and Kim, S-J. (2009) 'Context-aware systems: a literature review and classification', Expert Systems with Applications, Vol. 36, No. 4, pp.8509-8522.

Hsieh, H-C., Chen, C-M. and Hong, C-M. (2007) 'Context-aware ubiquitous English learning in a campus environment', in Seventh IEEE International Conference on Advanced Learning Technologies, 2007, ICALT 2007, pp.351-353.

Huang, Y-M., Kuo, Y-H., Lin, Y-T. and Cheng, S.C. (2008) 'Toward interactive mobile synchronous learning environment with context-awareness service', Computers \& Education, November, Vol. 51, No. 3, pp.1205-1226.

Illiyas, F.T., Mani, S.K., Pradeepkumar, A. and Mohan, K. (2013) 'Human stampedes during religious festivals: a comparative review of mass gathering emergencies in India', International Journal of Disaster Risk Reduction, Vol. 5, pp.10-18.

Jian, Y., Jintao, L., Hongzhou, S., Xiaoguang, G. and Zhenmin, Z. (2008) 'A fuzzy petri net model towards context-awareness based personalized recommendation', in Fifth International Conference on Fuzzy Systems and Knowledge Discovery, 2008, FSKD '08, pp.325-330.

Kandaswamy, K.K., Pugalenthi, G., Kalies, K-U., Hartmann, E. and Martinetz, T. (2013) 'EcmPred: prediction of extracellular matrix proteins based on random forest with maximum relevance minimum redundancy feature selection', Journal of Theoretical Biology, Vol. 317, No. 21, pp.377-383.

Khan, A.M., Tufail, A., Khattak, A.M. and Laine, T.H. (2014a) 'Activity recognition on smartphones via sensor-fusion and KDA-based SVMs', International Journal of Distributed Sensor Networks, Vol. 10, No. 5, pp.1-14.

Kiseleva, J., Thanh Lam, H., Pechenizkiy, M. and Calders, T. (2013) 'Discovering temporal hidden contexts in web sessions for user trail prediction', in Proceedings of the 22nd International Conference on World Wide Web Companion, pp.1067-1074.

Kitchenham, B. and Charters, S. (2007) Guidelines for Performing Systematic Literature Reviews in Software Engineering, Technical Report EBSE 2007-001, Keele University and Durham University Joint Report.

Kitchenham, B., Pickard, L. and Pfleeger, S.L. (1995) 'Case studies for method and tool evaluation', IEEE Software, Vol. 12, No. 4, pp.52-62.

Krause, A., Smailagic, A. and Siewiorek, D.P. (2006) 'Context-aware mobile computing: learning context-dependent personal preferences from a wearable sensor array', IEEE Transactions on Mobile Computing, Vol. 5, No. 2, pp.113-127.

Krausz, B. and Bauckhage, C. (2012) 'Loveparade 2010: Automatic video analysis of a crowd disaster', Computer Vision and Image Understanding, Vol. 116, No. 3, pp.307-319.

Kwon, J., Kim, S. and Yoon, Y. (2004) 'Just-in-time recommendation using multi-agents for context-awareness in ubiquitous computing environment', in Database Systems for Advanced Applications, pp.656-669.

Kwon, Y., Kang, K. and Bae, C. (2014) 'Unsupervised learning for human activity recognition using smartphone sensors', Expert Systems with Applications, Vol. 41, No. 14, pp.6067-6074.

Lee, J.H., Lee, H., Kim, M.J., Wang, X. and Love, P.E. (2014) 'Context-aware inference in ubiquitous residential environments', Computers in Industry, Vol. 65, No. 1, pp.148-157.

Lee, W-P., Chen, C-T., Huang, J-Y. and Liang, J-Y. (2017) 'A smartphone-based activity-aware system for music streaming recommendation', Knowledge-Based Systems, Vol. 2017, No. 1, pp.1-35.

Lin, W-C., Tsai, C-F., Ke, S-W. and You, M-L. (2015) 'On learning dual classifiers for better data classification', Applied Soft Computing, Vol. 37, pp.296-302.

Luštrek, M. and Kaluža, B. (2009) 'Fall detection and activity recognition with machine learning', Informatica, Vol. 33, No. 2, pp.197-204.

Mehmood, A. and Jawawi, D.N. (2013) 'Aspect-oriented model-driven code generation: a systematic mapping study', Information and Software Technology, Vol. 55, No. 2, pp.395-411. 
Mehran, R., Oyama, A. and Shah, M. (2009) 'Abnormal crowd behavior detection using social force model', IEEE Conference on Computer Vision and Pattern Recognition, 2009, CVPR 2009, pp.935-942.

Moitinho de Almeida, M.R.L. (2016) Human Stampedes: A Scoping Review, Erasmus mundus Master Programme Public Health in Disasters Degree Project, 20 credits, Submitted August 15, 2016, Center for Research on Health Care in Disasters, Karolinska Institutet, pp.1-35.

Mostefaoui, G.K., Pasquier-Rocha, J. and Brezillon, P. (2004) 'Context-aware computing: a guide for the pervasive computing community', in The IEEE/ACS International Conference on Pervasive Services, 2004, ICPS 2004, Proceedings, pp.39-48.

Musumba, G.W. and Nyongesa, H.O. (2013) 'Context awareness in mobile computing: a review', International Journal of Machine Learning and Applications, Vol. 2, No. 1, pp.1-10.

Naismith, L., Lonsdale, P., Vavoula, G. and Sharples, M. (2004) Literature Review in Mobile Technologies and Learning (Futurelab Series Report 11), pp.1-48, Futurelab, Bristol.

Nessi, F., Beretta, E., Gatti, C., Ferrigno, G. and Elena, D.M. (2016) 'Gesteme-free context-aware adaptation of robot behavior in human-robot cooperation', Artificial Intelligence in Medicine, Vol. 74, pp.32-43.

Neves, A.R.d.M., Carvalho, Á.M.G. and Ralha, C.G. (2014) 'Agent-based architecture for context-aware and personalized event recommendation', Expert Systems with Applications, 1 February, Vol. 41, No. 2, pp.563-573.

Noh, H-Y., Lee, J-H., Oh, S-W., Hwang, K-S. and Cho, S-B. (2012) 'Exploiting indoor location and mobile information for context-awareness service', Information Processing \& Management, January, Vol. 48, No. 1, pp.1-12.

Orwat, C., Graefe, A. and Faulwasser, T. (2008) 'Towards pervasive computing in health care - a literature review', BMC Medical Informatics and Decision Making, Vol. 8, No. 26, pp.1-19.

Petersen, K., Feldt, R., Mujtaba, S. and Mattsson, M. (2008) 'Systematic mapping studies in software engineering', in 12th International Conference on Evaluation and Assessment in Software Engineering.

Ramesh, M.V., Shanmughan, A. and Prabha, R. (2014) 'Context aware ad hoc network for mitigation of crowd disasters', Ad Hoc Networks, Vol. 18, pp.55-70.

Roggen, D., Wirz, M., Tröster, G. and Helbing, D. (2011) 'Recognition of crowd behavior from mobile sensors with pattern analysis and graph clustering methods', American Institute of Mathematical Sciences, September, Vol. 6, No. 3, pp.521-544, arXiv preprint arXiv:1109.1664.

Sadiq, F.I., Selamat, A. and Ibrahim, R. (2016) 'Context-awareness with activity recognition for mitigation of crowd disasters: a systematic literature review', in Proceedings of the 6th IGCESH 2016, International Graduate Conference on Engineering, Science and Humanities, N 24 Universiti Teknologi Malaysia, pp.298-300.

Satyanarayanan, M. (2002) 'Challenges in implementing a context-aware system', IEEE Pervasive Computing, Vol. 1, No. 3, p.2.

Schilit, B., Adams, N. and Want, R. (1994) 'Context-aware computing applications', in First Workshop on Mobile Computing Systems and Applications, 1994, WMCSA 1994, pp.85-90.

Schmidt, A. (2013) 'Context-aware computing: context-awareness, context-aware user interfaces, and implicit interaction', in Soegaard, M. and Dam, R.F. (Eds.): The Encyclopedia of Human-Computer Interaction, 2nd ed., The Interaction Design Foundation, Aarhus.

Sugimura, D., Kitani, K.M., Sato, Y. and Sugimoto, A. (2009) 'Using individuality to track individuals: clustering individyual trajectories in crowds using local appearance and frequency trait', Paper presented at the 2009 IEEE 12th International Conference on Computer Vision, 29 September 2009 to 2 October 2009, Kyoto, Japan.

Unger, M., Bar, A., Shapira, B. and Rokach, L. (2016) 'Towards latent context-aware recommendation systems', Knowledge-Based Systems, Vol. 104, pp.165-178.

Varshney, U. (2009) 'Context-awareness in healthcare', in Pervasive Healthcare Computing, pp.231-257, Springer, Boston, MA. 
Viswanathan, H., Baozhi, C. and Pompili, D. (2012) 'Research challenges in computation, communication, and context awareness for ubiquitous healthcare', Communications Magazine, IEEE, Vol. 50, No. 5, pp.92-99.

Wang, T.S-H., Tjondronegoro, D.W., Docherty, M. and Song, W. (2012) 'Uninav: a context-aware mobile application for university campus maps', in Internet of Things Workshop.

Wieringa, R., Maiden, N., Mead, N. and Rolland, C. (2006) 'Requirements engineering paper classification and evaluation criteria: a proposal and a discussion', Requirements Engineering, pp.102-107, Springer-Verlag London Limited 2005.

Wohlin, C., Runeson, P., Höst, M., Ohlsson, M.C., Regnell, B. and Wesslén, A. (2012) Experimentation in Software Engineering, Springer-Verlag Berlin Heidelberg, pp.1-236.

Ye, J., Dobson, S. and McKeever, S. (2012) 'Situation identification techniques in pervasive computing: a review', Pervasive and Mobile Computing, Vol. 8, No. 1, pp.36-66.

Zaharia, M.H., Leon, F., Pal, C., Pagu, G., Demiralp, M., Baykara, N. and Mastorakis, N. (2009) 'Agent-based simulation of crowd evacuation behavior', Proceedings of the 11th WSEAS International Conference on Automatic Control, Modelling and Simulation, pp.529-533.

\section{Notes}

1 C1-C75 are primary study dataset used in the SLR, details are in appendix.

$2 \mathrm{C} 1-\mathrm{C} 75$ are also used as citation in the text see appendix for detail.

\section{Appendix}

\section{Primary studies}

\section{Details of study dataset for the SLR}

C1 Roggen, D., Martin, W. and Gerhard, T. (2011) 'Recognition of crowd behaviour from mobile sensors with pattern analysis and graph clustering methods, networks and heterogeneous media, American Institute of Mathematical Sciences, September, Vol. 6, No. 3, pp.521-544.

C2 Chen, L. and Khalil, I. (2010) 'Activity recognition: practices and trends', Atlantis Press Review, 4 November, Vol. 9, No. 3, pp.1-24.

C3 Krausz, B. and Bauckhage, C. (2012) 'Loveparade 2010: automatic video analysis of crowd disaster', Computer Vision and Image Understanding, October 2011, Vol. 116, No. 3, pp.307-319.

C4 Maurer, U., Smailagic, A., Siewiorek, D.P. and Deisher, M. (2006) 'Activity recognition and monitoring using multiple sensors on different body position', Wearable \& Implantable Body Sensor Networks, 5 April, pp.113-116.

C5 Lee, J., Lee, H., Kim, M., Wang, X. and Love, P.E.D. (2014) 'Context-aware in ubiquitous residentials environments', Computers in Industry, 24 September 2013, Vol. 65, No. 1, pp.148-157.

C6 Se-Hoon, J. and Chun-Bo, S. (2011) 'Smart device oriented intelligent context-awareness system for U-safe service using object oriented modelling technique', ICHIT 2011, CCIS 206, Springer, pp.568-575.

C7 Adil, K.M., Ali, T., Asad, K.M. and Teemu, L.H. (2014) 'Activity recognition on smartphones via sensor-fusion and KDA-based SVM', International Journal of Distributed Sensor Networks, Hindawi, Vol. 10, No. 503291, pp.1-14. 
C8 Bao, L. and Intille, S.S. (2004) 'Activity recognition from user-annotated acceleration data', Pervasive 2004, LNCS 3001, Springer, pp.1-17.

C9 Fernandez-Caballero, A., Castillo, J.C. and Rodriguez-Sanchez, J.M. (2012) 'Human activity monitoring by local \& global finite state machines', Expert Systems with Applications, 15 June, Vol. 39 No. 8, pp.6982-6993.

C10 Abowd, D., Dey, A.K., Orr, R. and Brotherton, J. (1998) 'Context-awareness in wearable and ubiquitous computing', Virtual Reality, Springer-Verlag London Limited, Vol. 3, No. 3, pp.200-211.

C11 Kuo, J., Shih, C., Ho, C. and Chen, Y. (2014) 'A cross-layer middleware for context-aware cooperative application on mobile adhoc peer-to-peer network', Systems and Software, June, Vol. 92, pp.95-106.

C12 Hong, J., Suh, E-H., Kim, J. and Kim, S. (2009) 'Context-aware system for proactive personalized sevice based on context history', Expert Systems with Applications, Vol. 36, No. 4, pp.7448-7457.

C13 Leach, M.J.V., Sparks, E. P. and Robertson, N.M. (2014) 'Contextual anomaly detection in crowded surveillance scenes', Pattern Recognition Letters, 7 December, Vol. 44, pp.71-79.

C14 Hoyos, J.R., Garcia-Molina, J. and Botia, J.A. (2013) 'A domain-specific language for context modeling in context-aware systems', The Journal of Systems and Software, July, Vol. 86, No. 11, pp.2890-2905.

C15 Zhenyu, H. and Lianwen, J. (2009) 'Activity recognition from acceleration data based on discerete consine transformation and SVM', IEEE International Conference on Systems, Man \& Cybernetics, October, pp.5041-5044.

C16 Ki Yong, P. and Hee Youn, Y. (2011) 'Crime prevention system based on context awareness', Intelligent Systems and Applications 3rd International Conference, pp.1-4.

C17 Chao, C., Barnan, D. and Diane, C.J. (2010) 'A data mining framework for activity recognition in smart environments', Intelligent Environment (IE), IEEE xplore, 21 July, pp. $80-83$.

C18 Krishnamoorthy, S. and Agrawal, A. (2012) 'Context-aware technology enabled social contribution for public safety using M-urgency', Association of Computing Machinery, Proceedings of Mobile HCI, 24 September, pp.123-131.

C19 Maneesha, R.V., Anjitha, S. and Rekha, P. (2014) 'Context-aware adhoc network for mitigation of crowd disasters, Ad Hoc Networks, 14 March 2013, Vol. 18, pp.55-70.

C20 Li, C., Sun, L. and and Hu, X. (2012) 'A context-aware lighting control system for smart meeting rooms', Systems Engineering Procedia, Vol. 4, pp.314-323.

C21 Amr, E. and Mouftah, H. (2013) 'On resources management and context-awareness in LTEbased networks for public safety', 13th Annual IEEE Workshop on Wireless Local Networks, pp.973-979.

C22 Wang, C-Y., Hwnag, R-H. and Ting, C-K. (2011) 'UbipapaGo: context-aware path planning', Expert Systems with Applications, Vol. 38, No. 4, pp.4150-4161.

C23 Hyokyung, C., Hyosik, K., Changbok, J. and Euiin, C. (2012) 'Context-aware mobile platform for intellectual disaster alerts system', Energy Procedia, Vol. 16, pp.1318-1323.

C24 Mehta, S. and Banati, H. (2014) 'Context aware filtering using social behaviour of frogs', Swarm and Evolutionary Computation, August, Vol. 17, pp.25-36.

C25 Zubair, A. (2013) 'Disaster risk and disaster management policies and practices in Pakistan: a critical analysis of disaster management act 2010 of Pakistan', International Journal of Disaster Risk Reduction, 14 March, Vol. 4, pp.15-20.

C26 Henrickson, K. and Indulska, J. (2004) 'A software engineering framework for contextaware pervasive computing', Proceedings of the Second IEEE Computer Society Annual Conference on Pervasive Computing and Communications, pp.77-86. 
C27 Fabiana, M.G., Rossana, A.M.C., Claudia, W., Windson, V., Marcio, M.E.F., Lincoln, R.S., Eldanae, T., Joao, F.B., Valeria, D.L.L., Fabricio, L. and Saulo, A. (2013) 'Mobiline: a nested software product line for the domain and context-aware applications', Science of Computer Programming, May 2012, Vol. 78, No. 12, pp.2381-2398.

C28 Tuan, D.H., Seung, J.R. and Hyunchul, A. (2012) 'A novel recommendation model of location-based advertising: context-aware collaborative filtering using GA approach', Expert Systems with Applications, Vol. 39, No. 3, pp.3731-3739.

C29 Forkan, A.R.M., Khalil, I., Tari, Z., Foufou, S. and Bouras, A. (2015) 'A context-aware approach for long-term behavioural change detection and abnormality prediction in ambient assisted living', Pattern Recognition, 4 July 2014, Vol. 48, No. 3, pp.628-641.

C30 Fradi, H. and Dugelay, J. (2015) 'Towards crowd density video surveillance applications', Information Fusion, July, Vol. 24, pp.3-15.

C31 Iram, F., Muhammed, F., Young-Koo, L. and Sungyoung, L. (2013) 'Classifier esenmble optimization for human activity recognition in smart homes', Association of Computing Machinery, ICUIMC, 19 January, pp.1-7.

C32 Cardone, G., Cirri, A., Corradi, A., Foschini, L., Ianniello, R. and Montanari, R. (2014) 'Crowdsensing in urban areas for city-scale mass gathering management: geofencing and activity recognition', IEEE Sensors, December, Vol. 14, No. 12, pp.4185-4195.

C33 Noceti, N. and Odone, F. (2014) 'Humans in groups: the importance of contextual information for understanding collective activities', Pattern Recognition, May, Vol. 47, No. 11, pp.3535-3551.

C34 Jyh-Yeong, C., Jia-Jye, S. and Chien-Wen, C. (2009) 'Fuzzy rule inference based human activity recognition', IEEE International Conference on Systems and Control, 8 July 8, pp.211-215.

C35 Bessis, N., Assimakopoulou, E., Aydin, M.E. and Xhafa F. (2011) 'Utilizing next generation emerging technologies for enabling collective computational intelligence in disaster management', in Bessis, N. and Xhafa, F. (Eds.): Next Generation Data Technologies for Collective Computational Intelligence, Studies in Computational Intelligence, Vol. 352, Springer, Berlin, Heidelberg

C36 Roggen, D., Forster, K. and Calatroni, A. (2013) 'The AdARC pattern analysis architecture for adaptive human activity recognition systems', Journal of Ambient Intell Human Computer, Springer, Vol. 4, No. 2, pp.169-186.

C37 Gonzalo, G.B., Antonio, B. and Jose, M.M. (2011) 'Physical actions achitecture: contextaware activity recognition in mobile devices', User Centric Technologies and Applications, AISC, 94, Springer, pp.19-27.

C38 Toon, P.D., Simon, D. and Luc, M. (2014) 'Context-aware recommendations through context and activity recognition', Multimedia Tools Application, Vol. 72, No. 3, pp.2925-2948, Springer, US.

C39 Pozo, A., Gracia, J., Patricio, M.A. and Molina, J.M. (2011) 'Group behaviour recognition in contex-aware systems', IWANN, Part II LNCS, Springer, pp.645-652.

C40 Favela, J., Tentori, M., Castro, L.A., Gonzalez, V.M., Moran, E.B. and Martinez-Garcia, A.I. (2007) 'Activity recognition for context-aware hospital applications: issues and opportunities for the deployment of pervasive networks', Mobile Network Applications, Vol. 12, Nos. 2-3, pp.155-171, Springer, US.

C41 Surapa, T. and Guang-Zhong, Y. (2006) 'Context-aware sensing', Body Sensor Networks, pp.287-331, Verlag: Springer, London.

C42 Yu, X., Xu, B., Huang, W., Chew, B.F. and Dai, J. (2007) 'A framework of context-aware object activity recognition for smart home', ICOST 2007, LNCS 4541, Springer, pp.9-19. 
C43 Seungwok, H. and Hee, Y.Y. (2012) 'Petri net-based context modeling for context-aware systems', Artificial Intelligence Review, Vol. 37, No. 1, pp.43-67, Springer, Netherlands.

C44 Konlakorn, W., Junsoo, K., Yoshiki, M., Azman, L.O. and Yasuo, T. (2013) 'Architecture for organizing context-aware data in smart home for activity recognition system', HCII, LNCS 8028, Springer, pp.173-182.

C45 Pedro, C., Francois, P. and Michel, V. (2013) 'Making context aware decision from uncertain information in a smart home: a Markov logic network approach, LNCS, Springer, pp.78-93.

C46 Otebolaku, A.M. and Andrade, M.T. (2014) 'Context-aware media recommendation for smart devices', Journal of Ambient Intelligence Human Computer Interaction, Telecommunications \& Multimedia Unit, 16 May, Vol. 6, No. 1, pp.13-36, Springer, Berlin Heidelberg.

C47 Yuanyuan, C., Zhengjie, L. and Juhani, V. (2013) 'Activity based context-aware model', HCII 2013, Part I, LNCS 8012, Springer, pp.479-487.

C48 Zang, D. (2013) 'Context-aware computing in the era of crowd sensing from personal and space context to social and community context', 10th IEEE Workshop on Context Modeling and Reasoning, IEEE, 18 March, p.1.

C49 Riboni, D. and Bettini, C. (2011) 'COSAR: hybrid reasoning for context-aware activity recognition', Pervasive Ubiquitous Computing, Vol. 15, No. 3, pp.271-289, Springer-Verlag.

C50 Dey, A.K., Abowd, G.D. and Salber, D. (2001) 'A conceptual framework and toolkit for supporting the rapid prototyping of context-aware applications', Human Computer Interactions, Association of Computing Machinery, December, Vol. 16, No. 2, pp.97-166

C51 Meditsko, G., Stamatia, D. and Kompatsiaris, I. (2015) 'Meta Q: aknowledge-driven framework for context-aware recognition combining SPARQL and OWL 2 activity patterns', Pervasive and Mobile Computing, 23 January, Vol. 25, pp.1-19.

C52 Kose, M., Incel, O.D. and Eroy, C. (2012) 'Online human activity recognition on smart phones', 2nd International Workshop on Mobile Sensing, ACM, Association of Computing Machinery, Beijin, 1-5 April.

C53 Schilit, B., Adams, N. and Want, R. (1994) 'Context-aware computing applications', Mobile Computing Systems \& Applications, IEEE Workshop, 8 December, pp.85-90.

C54 Kawarehara, Y., Kurasawa, H. and Morikawa, H. (2007) 'Recognizing user context using mobile handsets with acceleration sensors', IEEE Transaction, May, pp.1-5.

C55 Bannach, D. and Lukowics, P. (2008) 'Rapid prototyping of activity recognition applications, Pervasive Computing, IEEE Computer Society, Vol. 7, No. 2, pp.22-31.

C56 Sama, M., Rosenblum, D.S., Wang, Z. and Elbaum, S. (2009) 'Multi-layer faults in the architecture of mobile', Context-Aware Adaptive Applications, November, Vol. 83, No. 6, pp.906-914.

C57 Ning, G., Vincenzo, D.F., Hong, S. and Chris, B. (2011) 'Towards architecture-based context-aware deployment and adaptation', Systems and Software, 21 September 2010, Vol. 84, No. 2, pp.185-197.

C58 Su, J-M. and Huang, C. (2014) 'An easy-to-use 3D visualization system for planning context-aware applications in smart buildings', Computer Standard \& Interfaces, 20 September 2012, Vol. 36, No. 2, pp.312-326.

C59 Hseih, F. and Lin, J. (2014) 'Development of context-aware workflow systems based on petri net markup language', Computer Standards \& Interfaces, August 2013, Vol. 36, pp.672-685.

C60 Espada, J.P., Crespo, R.G., Martinez, O.S., Pelayo, B.C.G. and Lovelle, J.M.C. (2012) 'Extenxible architecture for context-aware mobile web applications', Expert Systems with Applications, Vol. 39, pp.9686-9694. 
C61 Phan, T. (2014) 'Improving activity recognition via automatic decision pruning', Ubiquitous Computing, ACM, Association of Computing Machinery, 17 September, Vol. 14, pp.827-831.

C62 Lee, K., Kim, J., Lee, J. and Lee, K. (2007) 'Implementation of ontology based contextawareness framework for ubiquitous environment', International Conference on Multimedia and Ubiquitous Engineering, IEEE Computer Society, 28 April, pp.278-282.

C63 Yang, X. and Lianwen, J. (2010) 'A naturalistic 3D-based acceleration-based activity dataset and benchmark evaluations', System Man and Cybernetic (SMC), IEEE Xplorer, 13 October, pp.4081-4085.

C64 Yongjin, K., Kyuchang, K. and Changseok, B. (2014) 'Unsupervised learning for human activity recognition using smartphone sensors', Expert Systems with Applications, Vol. 41, No. 14, pp.6067-6074.

C65 Guiry, J.J., Vande Ven, P., Nelson, J., Warmerdam, L. and Riper, H. (2014) 'Activity recognition with smartphone support', Medical Engineering \& Physics, 9 February, Vol. 36, No. 6, pp.670-675.

C66 Jinhui, H. and Nikolaos, V.B. (2011) 'Fast human activity recognition based on structure and motion', Pattern Recognition Letters, 9 August, Vol. 32, No. 14, pp.1814-1821.

C67 Alvarez de la Conception, M.A., Soria, L.M.M., Gonzalez-Abril, L. and Ortega, J.A.R. (2014) 'Discrete techniques applied to low-energy mobile human activity recognition: a new approach', Expert Systems with Applications, Vol. 41, No. 14, pp.6138-6164.

C68 Carlo, T., Sabato, M. and Lorenzo, C. (2011) 'Smartphone-based applications for investigating falls and mobility', 5th International Conference on Pervasive Computing, pp.258-261.

C69 Unger, M., Bar, A., Shapira, B. and Rokach, L. (2016) 'Towards latent context-aware recommendation systems', Knowledge-Based Systems, Vol. 104, pp.165-178.

C70 Kamienski, C., Jentsch, M., Eisenhauer, M., Kiljander, J., Ferrera, E., Rosengren, P., Thestrup, J., Souto, E., Andrade, W.S. and Sadok, D. (2017) 'Application development for the internet of things: a context-aware mixed criticality systems development platform', Computer Communications, Vol. 104, pp.1-16.

C71 Cavaliere, D., Senatore, S. and Loia, V. (2017) 'Context-aware profiling of concepts from a semantic topological space', Knowledge-Based Systems, Vol. 2017, pp.1-14.

C72 Böhmländer, D., Dirndorfer, T., Al-Bayatti, A.H. and Brandmeier, T. (2017) 'Contextaware system for pre-triggering irreversible vehicle safety actuators', Accident Analysis and Prevention, Vol. 103, pp.72-84.

C73 Cao, L., Wang, Y., Zhang, B., Jin, Q. and Vasilakos, A.V. (2017) 'GCHAR: an efficient group-based context-aware human activity recognition on smartphone', J. Parallel Distrib. Comput. [online] https://doi.org/10.1016/j.jpdc.2017.05.007 (accessed 26 May 2017).

C74 Lee, W-P., Chen, C-T., Huang, J-Y. and Liang, J-Y. (2017) 'A smartphone-based activityaware system for music streaming recommendation', Knowledge-Based Systems, Vol. 2017, pp.1-35.

C75 Nessi, F., Beretta, E., Gatti, C., Ferrigno, G. and Elena, D.M. (2016) 'Gesteme-free contextaware adaptation of robot behavior in human-robot cooperation', Artificial Intelligence in Medicine, Vol. 74, pp.32-43. 